\title{
02 | El pabellón Niels Bohr. Tradición Danesa y Modernidad
}

\section{Carmen García Sánchez}

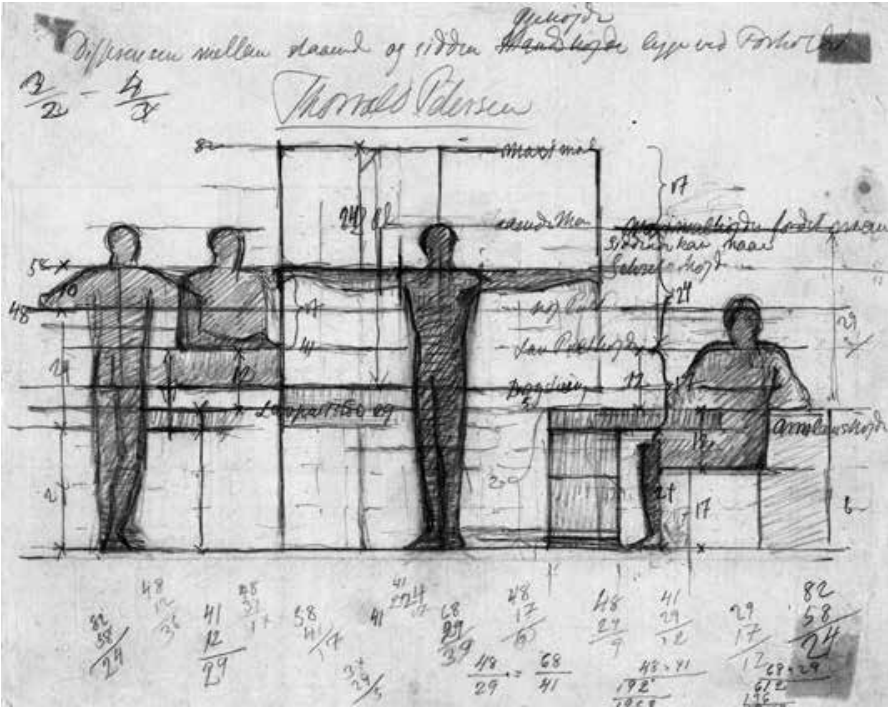

[1]

La casa de invitados de Niels Bohr (1957) fue el primer proyecto construido del arquitecto danés Vilhelm Wohlert (1920-2007). Pese a su pequeña escala, ya expresaba la esencia de la arquitectura que desarrollará posteriormente, en su mayoría junto a su amigo el arquitecto Jørgen Bo (1919-1999). Arraigada a la tradición danesa y a los principios de la Skønvirke', su obra representa una renovación basada en la absorción de influencias extranjeras: la arquitectura Americana y la tradición Japonesa.

Wohlert había conocido los principios fundamentales de la arquitectura tradicional danesa de la mano de su mentor, Kaare Klint² (1888-1954), fundador de la Escuela de Mobiliario en 1920 , dentro de la Real Academia de las Bellas Artes en Copenhague ${ }^{3}$. Klint le enseñó a planificar sus proyectos utilizando módulos basados en el uso del espacio, especialmente en el diseño de muebles [1]; a valorar y emplear los materiales y sus texturas, atendiendo al estudio de sus detalles y juntas; y a buscar la inspiración en otras culturas y épocas ${ }^{4}$. Su padre era Jensen Klint (1853-1930), creador de la Bygmesterskolen 1911 -escuela de construcción-, cuyo trabajo representaba un elemento clave en la evolución de la moderna Dinamarca, siendo su proyecto de la iglesia de Grundtvig su emblema ${ }^{5}$. [2]

La obra de Wohlert no solo se extiende al ámbito de la obra nueva de arquitectura, que desarrolla tanto en Dinamarca como en el extranjero, también restaura edificios y monumentos históricos y diseña pequeños accesorios y muebles ${ }^{6}$. Tratándose de muy diferentes escalas y funciones, todo su trabajo muestra su compromiso con el confort humano, la búsqueda de precisión en la construcción y el respeto por los materiales, características que en ninguna de sus obras serán más claras que en la modesta casa de invitados que proyecta para el profesor Niels Bohr (18851962), padre de la teoría cuántica y ganador del Premio Nobel de Física en 1922.

Fue en el invierno de 1956 cuando Bohr conoció a Wohlert a través de su amigo el escultor danés Jørgen Gudmundsen-Holmgreen ${ }^{7}$ (1895-1966), que estaba trabajando en el impresionante busto de Bohr, ubicado ahora en el frente de la Universidad de Copenhague. Wohlert había realizado la Óptica Thiele en 1956, continuando el trabajo de Kaare Klint, y ya estaba realizando la restauración de la casa principal Louisiana, que se convertiría en un nuevo museo de arte moderno. El profesor le encargó a Wohlert la renovación de su casa de verano en Tisvilde, en la costa del norte de Sjælland, y el diseño de una nueva ala de invitados. La casa a ampliar, construida con los fondos del Premio Nobel, había sido diseñada por el arquitecto danés Edvard Thomsen (1884-1980). Consistía en una edificación de dos plantas, cubierta inclinada de paja, muros de ladrillo encalados en blanco y elementos de madera embreada; una paleta de materiales típica danesa. La parcela quedaba integrada en una remota extensión de bosque virgen, Tisvilde Hegn, la más amplia de Sjælland. Allí, además de la casa principal, se distribuían libremente otras construcciones. Wohlert proyectó un edificio para invitados separado, preservando la integridad de la casa existente, y
Resumen pág 42 | Bibliografía pág 48

Carmen García Sanchez es arquitecto desde 1997, por la Escuela Técnica Superior de Arquitectura de Madrid, obteniendo sobresaliente en el proyecto de fin de carrera. En la actualidad realiza su Tesis Doctoral en el Departamento de Proyectos Arquitectónicos de la E.T.S.A.M. bajo el título: "1950 en torno al Museo Louisiana 1970". En ella analiza una serie de edificios que se construyeron en Dinamarca, al norte de Copenhague, entre 1950 y 1970. En 2013 recibió una beca de investigación del Gobierno Danés en la Universidad de Copenhague, realizando una estancia internacional allí para el desarrollo de su tesis.

\section{Palabras clave:}

Niels Bohr, Vilhelm Wohlert, tradición danesa, tradición japonesa, flujo, ikebana, naturaleza

1 Skønvirke es el movimiento artístico versión danesa del Arts\&Crafts de William Morris y la Deutscher Werkbund de Hermann Multhesius. En 1901 Jensen Klint fundó la Sociedad para las Artes Decorativas (Society for Decorative Art) con sus amigos Jens Møller Jensen, Thorvald Bindesbell y otros arquitectos y artesanos, introduciendo el concepto de "Skønvirke", la belleza (skønhed en danés) de su esfuerzo (virke), que representará el periodo de desarrollo de la expresión personal del arte.

2 Kaare Klint creía en la evolución histórica de la forma, y defendia el estudio de las proporciones y medidas del cuerpo humano como medio y herramienta vital para alcanzar en la producción industrial el equilibrio entre el diseño y las proporciones humanas. Mientras que en Dinamarca como país escandinavo había una gran tradición del trabajo con madera, la influencia del diseño de muebles, al igual que a muchos de sus contemporáneos alumnos de K. Klint, le hizo entender a Wohlert la gran importancia de la artesanía y le transmitió una profunda preocupación por hacer juntas entre los diferentes elementos constructivos.

3 Donde se integraba la Escuela de Arquitectura.

${ }^{4}$ Wohlert era un intrépido viajero y tras graduarse en arquitectura visitó Europa (allí conoció la arquitectura Mediterránea), el norte de África y América, afincándose en California donde impartió clases en la universidad de Berkeley durante dos años.

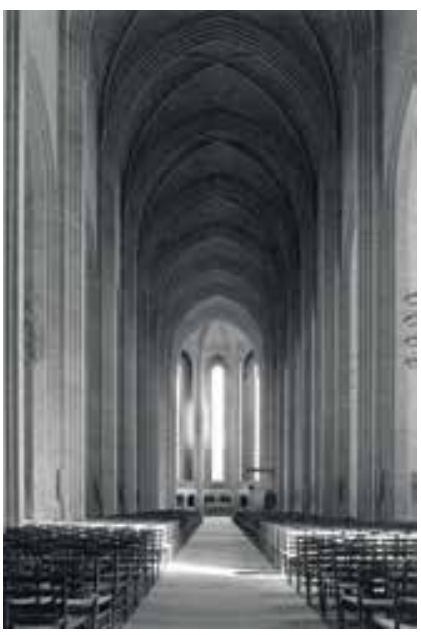


logrando más privacidad tanto para la familia como para los huéspedes, tal y como quería el profesor -se ubicaría en un claro cercano orientado al sudoeste, para disfrutar del sol de la tarde-. Su construcción debía terminarse para el verano y tener un presupuesto ajustado.

5 P. V. Jensen Klint, artista pionero, educador y creador de opiniones, fue de una enorme relevancia en la arquitectura y el diseño danés como una figura de transición en un periodo que se extendia entre una aguda conciencia de la historia y un impulso por la liberación, simplicidad y responsabilidad social. Él representaba los mejores elementos de la tradición; el respeto por el entorno, la artesanía el material y la importancia de los detalles. Todos estos elementos fueron gradualmente incorporándose, como una parte natural de la ética y la aproximación estética hacia la arquitectura y el diseño danés. Klint recuperaba la mirada hacia la arquitectura rural: las granjas, iglesias y las casas señoriales, donde la construcción, los materiales y los efectos de texturas y colores podian rescatar la forma y el contenido funcional. La creación de la Bygmesterskolen supuso un cambio en el modelo educativo danés donde utilidad, durabilidad y diseño se desarrollarían aplicando la tradición artesanal. Pero había que avanzar a partir de lo conocido, asi, la iglesia de Grundtvig (19201940), en Copenhague, casi del tamaño de una catedral, representa el resurgimiento de la tradición danesa del ladrillo, convirtiéndose en un edificio de transición entre la tradición arquitectónica y la expresión moderna del uso de un solo material, que además guarda otras cualidades especiales. Hace uso de un material deliberadamente humilde para realizar una casa espiritual y elevarla a un nivel trascendental mediante el desarrollo de sus detalles y el trabajo artesano del más alto nivel.

${ }^{6}$ Entre otras obras diseñó alrededor de 100 lámparas, armarios, estanterias y sillas o restauró la catedral de Copenhague (1993) y la de Roskilde (1991). En compañía de Jørgen Bo realizó el Museo de Arte Moderno Louisiana (1958-1998) y numerosos proyectos residenciales en Dinamarca, además del Museo Bochum en Alemania (1982); también realizó edificios en solitario o colaborando con otros arquitectos.

${ }^{7}$ Gudmundsen- Holmgreen había conocido a Wohlert mientras ambos trabajaban en el museo Ny Carlsberg

${ }^{8}$ Christian Norberg Schulz habla de la identificación con el medio ambiente, además de la orientación, como un requisito necesario para el acto de morar, relación total entre el hombre y el lugar.

${ }^{9}$ Los muretes, de 25 centimetros de espesor recorren toda la longitud del edificio y se entierran por debajo de la línea de penetración de las heladas, sobresaliendo de la rasante unos 30 centímetros. Se reducen asi los costes de cimentación, a la vez que se consigue una separación del terreno necesaria para evitar la pudrición. espiritu artístico.

[1] Dibujo de estudios de proporciones humanas para la fabricación de unos muebles en 1918, realizados por Kaare Klint. PAAVILAINEN, S, et al, 1982. Nordisk Klassicism, 1910-1930 - Nordic Classicism, 1910-1930. Helsingfors, Finlandia. p. 69. Dibujo original Helsingfors, Finlandia. p. 69. Dibujo original
propiedad de la Biblioteca de Arte Naciona Danesa, Colección de dibujos de arquitectura.

[2] Imagen interior de la Iglesia de Grundtvig, de Jensen Klint. SHERIDAN, M., 2011. Mesterværker, Enfamiliehuset i Dansk Arkitekturs Guldalder: Copenhague: $p$. 18. Fotogra Guldalder. Copenhague: p. 18. Fotografia original propiedad de la Biblioteca de Arte Nacional Danesa, Archivo de fotografias histórico artísticas.

[3] Croquis del plano de situación del pabellón Niels Bohr realizado a lápiz. Autor Vilhelm Wohlert. NYBORG, A. et al., 1987. Selections. Copenhage: Anders Nyborg Private Edition p. 10.

El arquitecto diseñaría un enigmático pabellón, situado al norte de la casa principal -girado respecto a esta un ángulo de 60 grados- que, sin perder el contacto con ella, ofrecería a los huéspedes la oportunidad de aislarse y aprovechar la luz solar. Wohlert destacaba el interés de su cliente por el diálogo que se establecería entre los dos edificios. [3] [4]

Llegando desde la carretera de acceso, el pabellón queda escondido a la derecha tras unos árboles, solo al alcanzar la casa familiar se descubre al fondo, por sorpresa. Desde allí los invitados recibidos por el anfitrión deben aproximarse al edificio paseando por un sendero, despojándose de su actitud mental, para alcanzar así un grado de intimidad con el edificio y lograr la identificación con el lugar ${ }^{8}$ [5]. El que alcanzar la cercanía requiera un sentido de la distancia ya lo defendía el filósofo alemán Martin Heidegger (1889-1976).

En lugar de tomar referencias del trabajo de Thomsen o de arquitecturas tradicionales de los alrededores de la zona, Wohlert realiza una pieza abstracta, independiente, que preserva el espacio abierto de alrededor, creando un nuevo lugar donde convivirán arquitectura y naturaleza. La solución adoptada parece engañosamente simple: una compacta caja de madera que simula flotar sobre la plataforma del terreno, cuya fachada delantera se abre al sudoeste, acompañada de una gran terraza corrida que busca el sol y la conexión con el bosque, y la trasera, opaca y maciza, se cierra al nordeste; pero es mucho más que eso. El volumen de madera descansa, despegándose del terreno, sobre tres muretes de hormigón ${ }^{9}$. Al elevarse permite que el espacio de alrededor continúe por debajo, asentándose en el claro de la parcela sin destruir la esencia del lugar [6]. Varios recursos enfatizan la ligereza y sensación flotante de la caja de madera: el modo en que vuela simétricamente sobre la base maciza de hormigón en su fachadas sudoeste y nordeste; la reducción, al llegar a sus extremos, tanto del ancho de los muretes de cimentación como del canto de la viguetas del suelo; su composición liviana, realizada íntegralmente de madera y revestida con tablas en vertical; y la delicada forma de ascender a ella, mediante dos peldaños aislados. [7] [8] [9] [10]

Wohlert utiliza, al proyectar la planta, un módulo ordenador $1: 2,1.040 \mathrm{~mm} \times 2.080 \mathrm{~mm}^{10}$. Su proporción y dimensiones al modular las plantas se refleja ya en sus proyectos de la academia, pero la severidad modular que ordenaba sus proyectos de estudiante tanto en fachadas como plantas, ahora ha perdido su rigidez visual. Wohlert sigue las enseñanzas de Klint sin perder su espíritu artístico. La proporción y dimensiones del módulo utilizado, al igual que el tatami que ordena la casa tradicional japonesa, vienen dadas por la estandarización de la construcción en madera, gobernada por el deseo de trabajar con longitudes y medidas enteras ${ }^{10}$ [11]. El ancho del módulo coincide con el producto de los tablones de madera de fachada, cinco tablones de 208 milímetros cada uno. Tres módulos generan el ancho de cada habitación; y cuatro módulos el fondo, resultando 5 divisiones de las mismas dimensiones. La planta de la superficie cerrada es un rectángulo de aproximadamente 15,60 m x 4,16 m. Las dimensiones de las puertas, contraventanas y terraza también las regula el módulo"11. Este modo lógico de dimensionarlo asegura que todo se ajusta y encaja sin tener que cortar y desperdiciar material, como un mecano. Combina las antiguas técnicas de construcción en madera con precisos detalles típicos de los ebanistas, como la realización de juntas de cola de milano a modo de cremallera en las

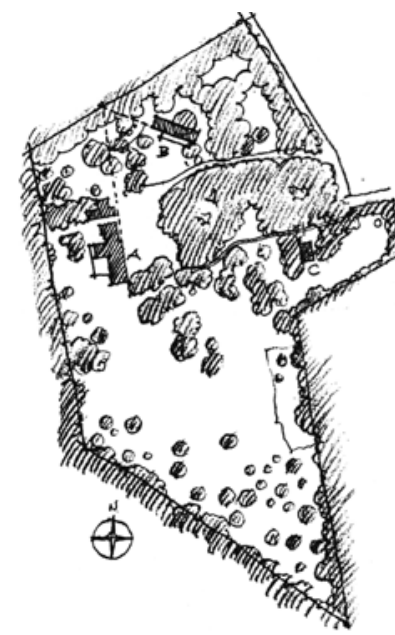

[3]

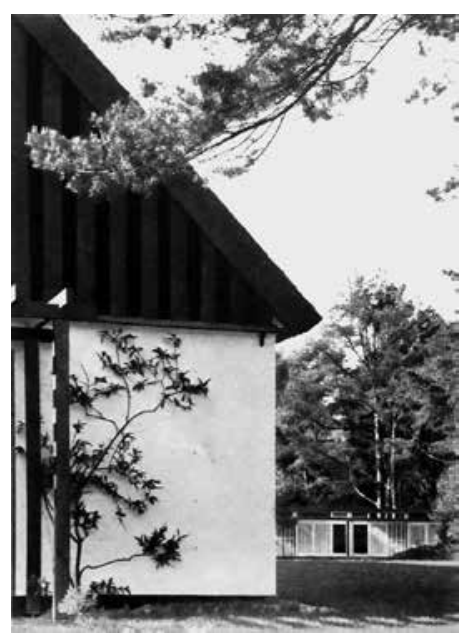

[4]

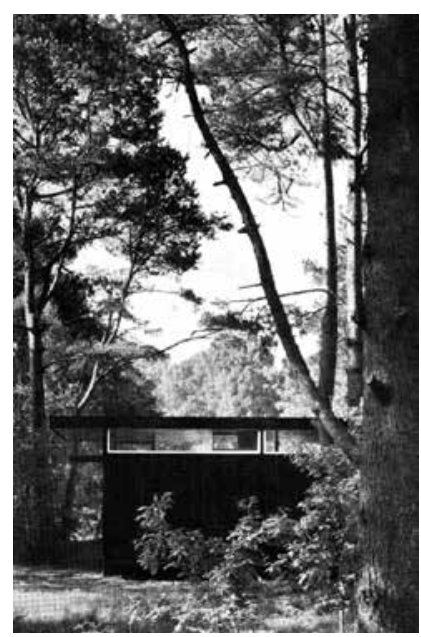

[5] 


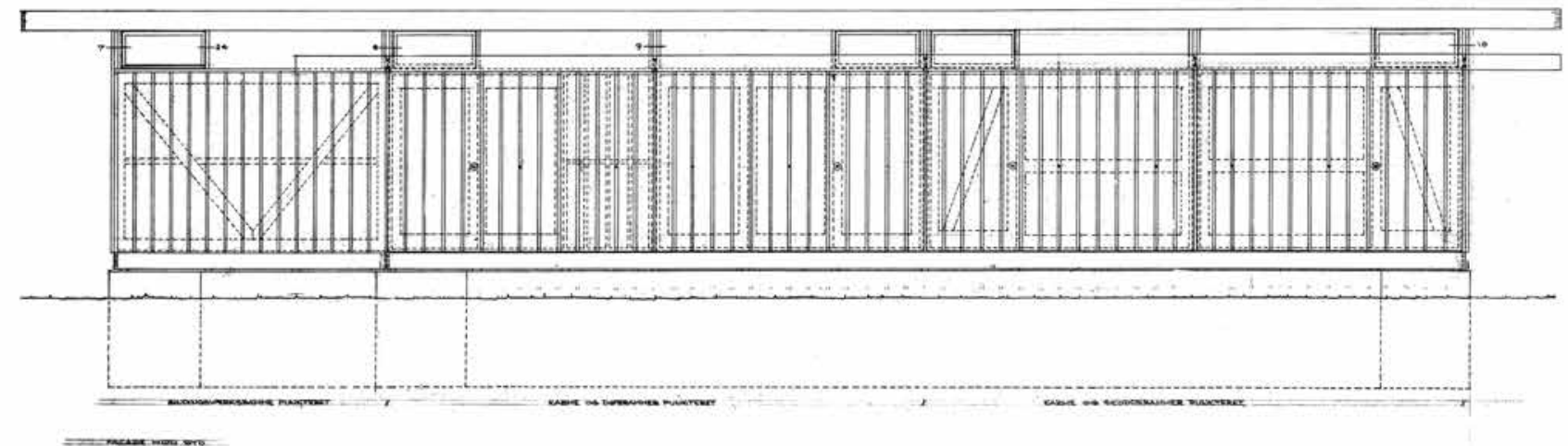

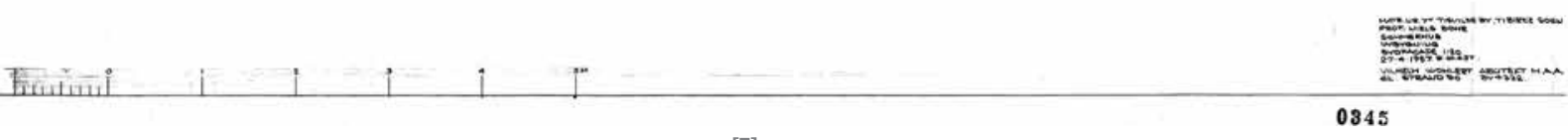

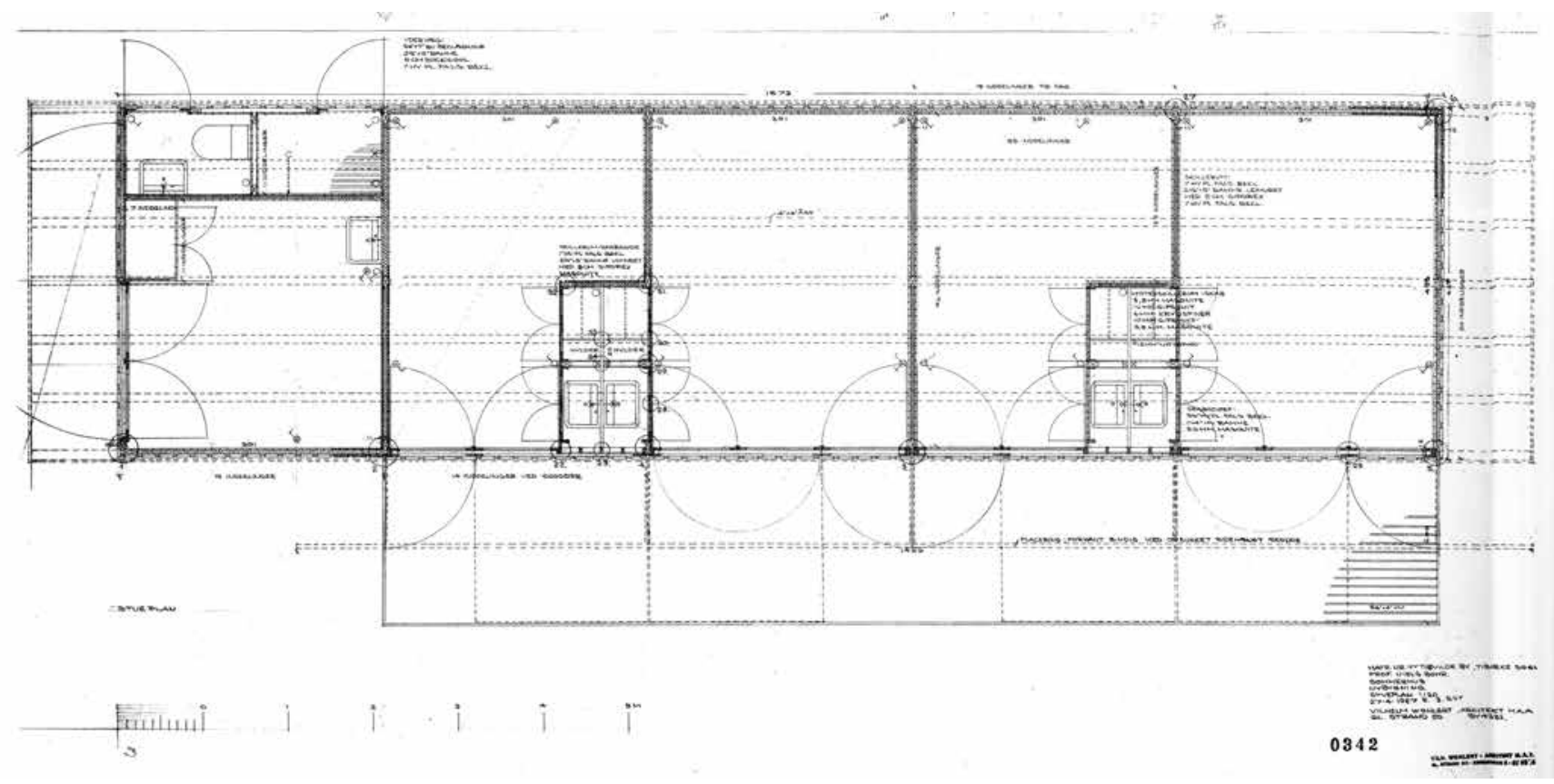

[8]

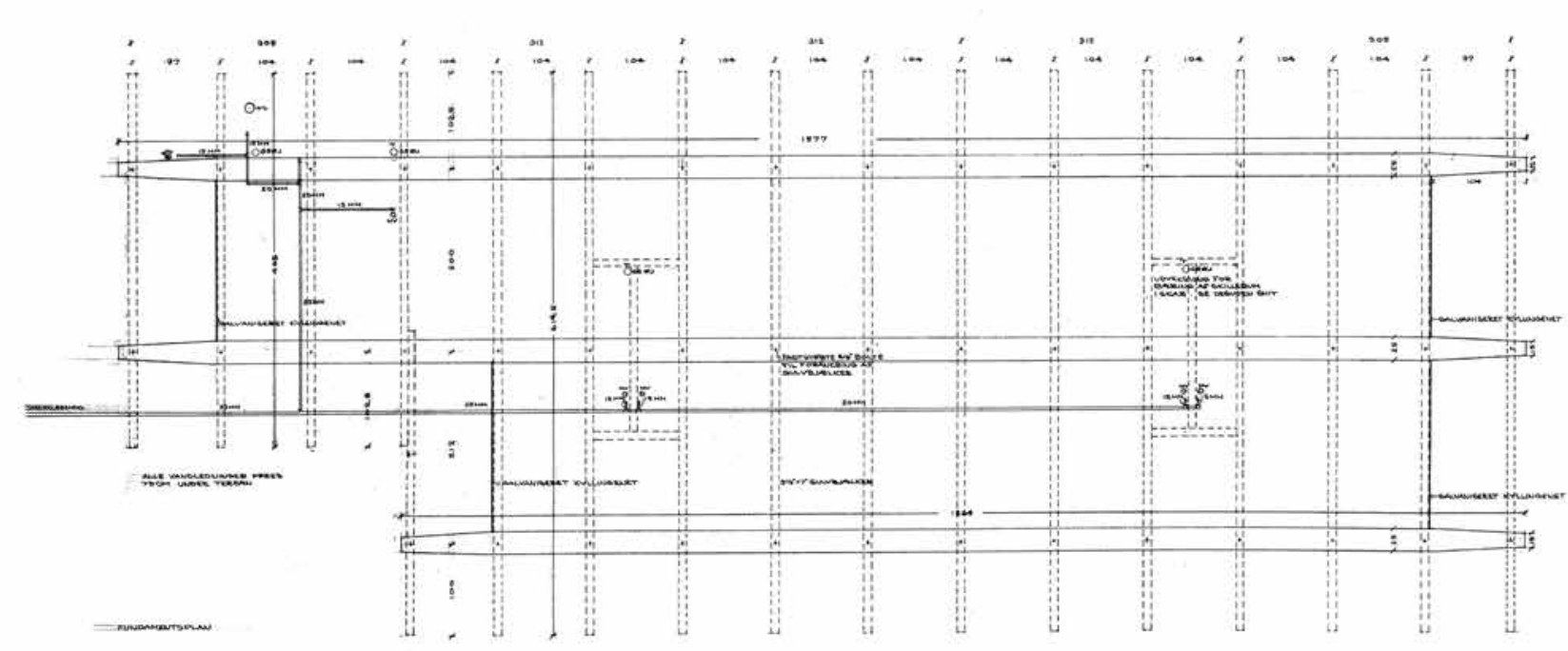

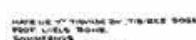

D.t.

xistion 0341 - 
[4] Imagen de la casa familiar y el pabellón Niels Bohr. Fotografia de Jesper Høm. WO HLERT, V., "1958. Annex Til Sommerbolig i Tibirke Lunde". Arkitektur DK 1958 n 4. Copenhage: Arkitektens Forlag. p. 140.

[5] Imagen del pabellón Niels Bohr. Fotografía de Jesper Høm. MONIES, F., Træ Og Arkitektur. Copenhage: Træbranchernes oplysningsråd og Arkitektens Forlag, 1958, p. 30.

[6] Alzados laterales proyecto pabellón Niels Bohr. Autor Vilhelm Wohlert. PARDEY, J.,et al. Louisiana and Beyond: The Work of Vilhelm Wohlert. Hellerup (Dinamarca): Blondal, 2007, p.25.

${ }^{10} \mathrm{Si}$ comparamos el tamaño del módulo con el del tatami japonés, es algo mayor que este, adecuándose a la talla de los daneses. Se aproxima más a las medidas de Kioto que a las de Tokio. En Kioto se mantiene en gran medida el "viejo gusto Imperial", más cómodo y más digno, con la dimensión del tatami mayor que mide 6,3 pies japoneses o 1,91 metros. Anteriormente el tatami llegó a medir 6,5 pies japoneses o casi dos metros de longitud. En Tokio son más austeros y utilizan tatami de solo 6 pies japoneses o 1,82 metros. Debido a la mayor influencia de Tokio las longitudes de la ropa de cama, independientemente de las medidas constructivas, se rigen por su tatami.

11 La terraza tiene el ancho de dos módulos equivalentes a dos tatamis, al igual que el engawa de algunas casas japonesas. Su superficie es de $26 \mathrm{~m} 2,12$ módulos.

12 (RASMUSSEN, S. E., p 9-34)

${ }^{13} \mathrm{La}$ altura baja corresponde a la altura de las puertas, $2.008 \mathrm{~mm}$., las paredes tienen el mismo acabado del techo, panelado con tablas

de madera verticales; la alta, de unos $502 \mathrm{~mm}$. de altura, la mitad del módulo, a modo de friso, está acabada en tablero de yeso.

14 Las casas tradicionales japonesas "han sido tomadas como modelos para sus casas de té por los espiritus más cultivados del país" (TAUT, B., p 141).

15 El pino es una pintoresca alegoría en Japón, símbolo de larga vida y de firmeza frente a las tormentas y las tempestades. Los tapices actualmente ya no se conservan.

${ }^{16}$ Wohlert explicaba que cuando el profesor Thomsen diseñó la finca antigua, antes de su época más moderna, también usó un tapiz francés con motivos florales, y que, con la intención de mantener la misma atmósfera en el pabellón, usó una litografía de friso.

${ }^{17}$ Los artistas nipones prefieren hacer sus dibujos sobre imágenes de la nieve, casi siempre prescinden del color en el arte japonés más serio. La imagen más delicada para Bruno Taut es la de los pinos en la nieve.

${ }^{18}$ Son muebles de la fábrica de Søborg Møbelfabrik de principios de los 50 .

${ }^{19}$ Las cuatro que dan a la terraza están organizadas por parejas de dos: una habitació más grande con dos camas estándares y una habitación más pequeña con dos camas literas.
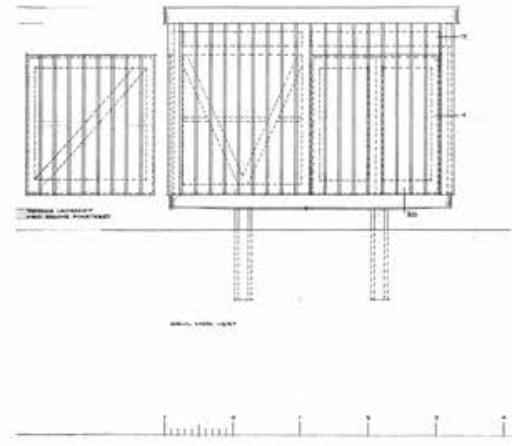

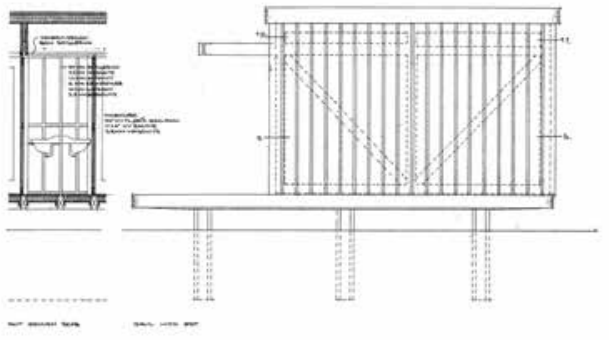

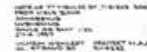

$0344=2=$

[6]

uniones de las tablas perimetrales. Atendiendo a un cuidado diseño y la valoración de las juntas, crea una elegante conciliación entre lo rústico y refinado. Pero lo más destacable es la gran unidad del conjunto prevaleciendo una transición equilibrada entre sus partes que proporciona armonía y equilibrio a todo el edificio. Al igual que sucede en la casa tradicional japonesa, se ajusta a la medida del hombre, ahí reside la clave de su efecto estético, transmitiendo serenidad y belleza. [12] [13] El concepto de belleza de la cultura ancestral danesa procede del mundo vikingo; estos pueblos bárbaros tienen una cultura material muy precisa desde el punto de vista del hacer artesanal constructivo. El término danés brugkunst, el arte de crear un objeto para ser usado, explica esta actitud donde lo funcional y lo bello van unidos, y la forma es producto de la precisión técnica. Los postulados vikingos reaparecen en Dinamarca con el Funcionalismo, en la primera mitad del siglo XX. S. E. Rasmussen (1898-1990) va más allá, formulaba en 1957 que la arquitectura "es un arte que apela a la vista y tiene que ver con "la belleza", pero no solo le concierne el tema de la apariencia, también debe armonizar entre sí, y con el entorno ${ }^{12 "}$

Las paredes interiores se dividen en dos alturas ${ }^{13}$, coincidiendo con las proporciones del pabeIlón de té japonés ${ }^{\mathbf{1 4}}$. Esta división se transmite al exterior, con la banda horizontal de ventanas estrechas del frente y la parte trasera del pabellón, que iluminan y permiten la ventilación cruzada [14]. Para enfatizar la subdivisión, Wohlert empapeló, a modo de friso, la franja superior con motivos de ramas de pino sobre fondo blanco de inspiración japonesa ${ }^{\mathbf{1 5}}$, dibujados por él mis$\mathrm{mo}^{16}$-el empapelado con motivos de naturaleza es un recurso utilizado en la arquitectura tradicional nipona, puede tener sutiles variaciones de color y forma y añade expansividad y vitalidad a lo sencillo, significando el interior ${ }^{17}$ [15]-. Para distinguirlos desde la terraza asigna a cada dormitorio un color diferente, de modo que el empapelado se imprime en el color que le corresponde, siendo los tapices los únicos elementos de color en las blancas paredes de las habitaciones -su sobriedad cromática, unida a su austeridad, transmite serenidad-. Equipadas con muebles de teca ${ }^{\mathbf{1 8}}$ del diseñador danés Børge Mogensen (1914-1972), se caracterizan por su sencillez y ascetismo. Dotadas de lo más necesario, casi parecen camarotes ${ }^{19}$. Cada una de ellas tiene

[11]

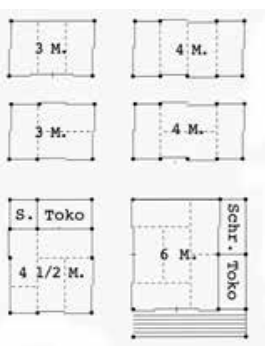

[9] Dibujo de planta esquema de modulación, por la autora del artículo, 2015.

[10] Planta de cimentación pabellón Niels Bohr. Autor Vilhelm Wohlert. ARDEY, J., et al., Louisiana and Beyond: The Work of Vilhelm Wohlert. Hellerup (Dinamarca): Blondal, 2007, p. 26

[11] Tamaño de habitaciones de una vivienda basado en la modulación del tatami japonés. YOSHIDA, T., Das Japanische Wohnhaus. Berlin: Verlag Ernst Wasmuth, 1935 , p. 53
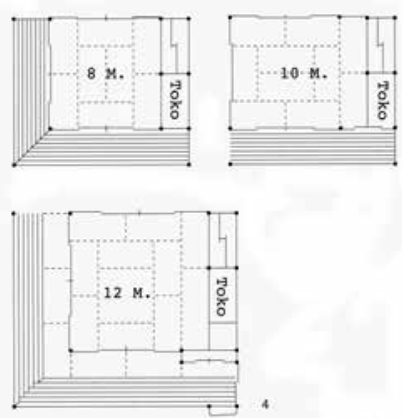

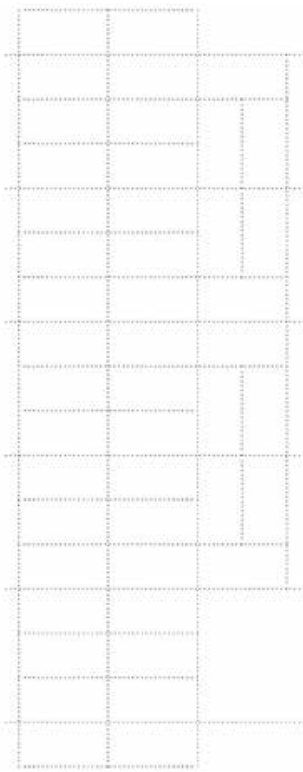




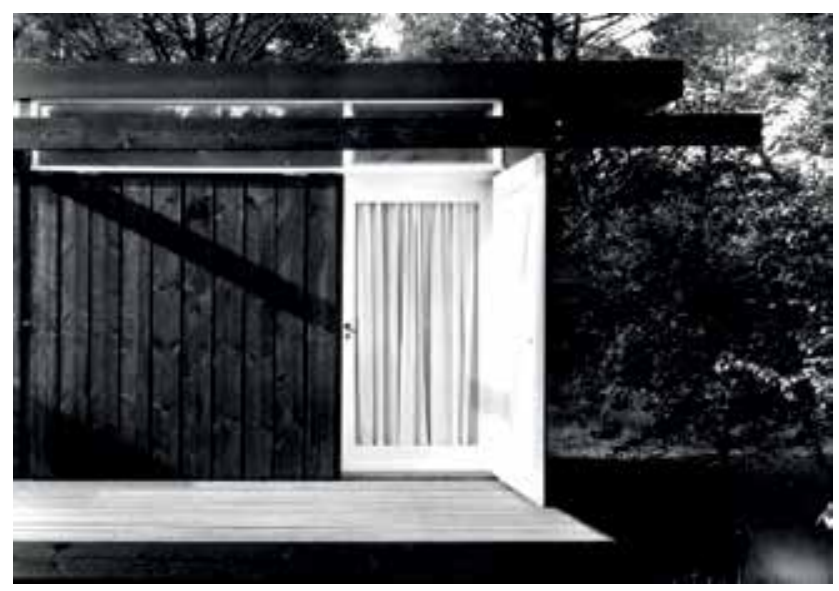

[12]

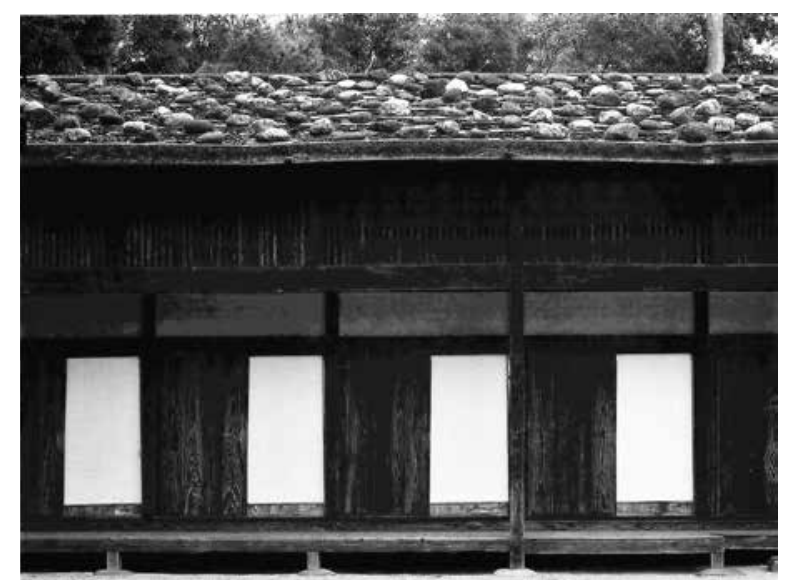

[13] un armario empotrado, y oculto tras unas puertas y un lavabo que recibe luz natural a través de una celosía en fachada, de madera y vidrio al ácido. Aunque las paredes están aisladas térmicamente y las estancias están equipadas con radiadores eléctricos, el edificio carece de muchas características típicas de una casa, así el movimiento de una habitación a otra, o ir al aseo obliga a salir al exterior ${ }^{20}$. Por ello recuerda a la naturaleza de un refugio, un lugar donde sentirnos protegidos y al mismo tiempo lugar de relación con la naturaleza y el mundo, un mirador.

Los elementos estructurales y el revestimiento de fachada, tratados con un protector alquitranado, muestran un inquietante color negro; mientras que el marco de las ventanas y las superficies interiores están pintadas al esmalte en color blanco. La elección de estos acabados se basa exteriormente en métodos de protección de las maderas blandas, e interiormente en la refracción de la luz. Pero la paleta cromática negra y blanca, coincidente con el exterior de la casa principal, también proporciona una deliberada atención a las variaciones de color e iluminación de la naturaleza, registrando los pequeños cambios del clima y subrayando el paso de las horas del día o de las estaciones. [16]

Una doble capa de hojas, que se pueden practicar independientemente, componen el cerramiento vertical. En la fachada frontal la capa exterior la conforman sólidas contraventanas. Las de mayor dimensión (cuatro, de dos módulos de ancho) se elevan manualmente para formar un plano horizontal que vuela sobre la terraza ${ }^{21}$-cuando se despliegan proporcionan sombra y refugio de las lluvias ocasionales, configurando temporalmente un porche-. Otras contraventanas, de la mitad de tamaño, se abaten en su eje vertical hacia el exterior, creando dos espacios exteriores del ancho de dos dormitorios, para independizar a las dos posibles familias de huéspedes y proteger de la brisa. Detrás de estos sólidos paneles hay una segunda capa compuesta de puertas acristaladas: fijas, basculantes y plegables (a modo de biombos), simulando puertas japonesas shoji, que se pliegan hacia el interior de los dormitorios ${ }^{22}$ [17]. Gracias al sistema de contraventanas y puertas
[12] Detalle extremo alzado sur pabellón Niels Bohr. Fotografia de Jesper Høm.

[13] Imagen alzado antigua residencia Arai, en Nagatoro-cho Chichibu-gun. Prefectura Saitama, Japón. KUMA, K. et al., Kyokai: $A$ Japanese Technique for Articulating Space. Japón: Tankosha. Publishing Co., 2010, p.57 Cortesía de Tankosha Publishing Co ed.

[14] Plano de secciones transversales pabellón Niels Bohr. Autor Vilhelm Wohlert. PARDEY, J., et al., Louisiana and Beyond: The Work of Vilhelm Wohlert. Hellerup (Dinamarca): Blondal, 2007, p. 24.

${ }^{20}$ Los japoneses tradicionalmente calientan su ropa y se abrigan pero no calientan el aire del interior de la casa. Las casas en otoño las siguen abriendo para que estén aireadas y se calienten con el sol. Pero se pasa frío si no se viste adecuadamente. Ellos se superponen varios kimonos y van abrigados, en consonancia con la teoría térmica más moderna, según la cual no es la temperatura del aire la que da el confort sino el calor irradiado. Esta situación establece una relación de cercanía a la naturaleza mayor.

21 Quedando suspendidas de los marcos superiores y ancladas a la parte baja de una viga estabilizadora.

22 En los dormitorios grandes el cerramiento se divide en tres partes iguales (tres módulos), una parte conforma una puerta de paso y las otras dos componen dos hojas unidas que a modo de biombo se pliegan para doblarse y quedar completamente encajadas

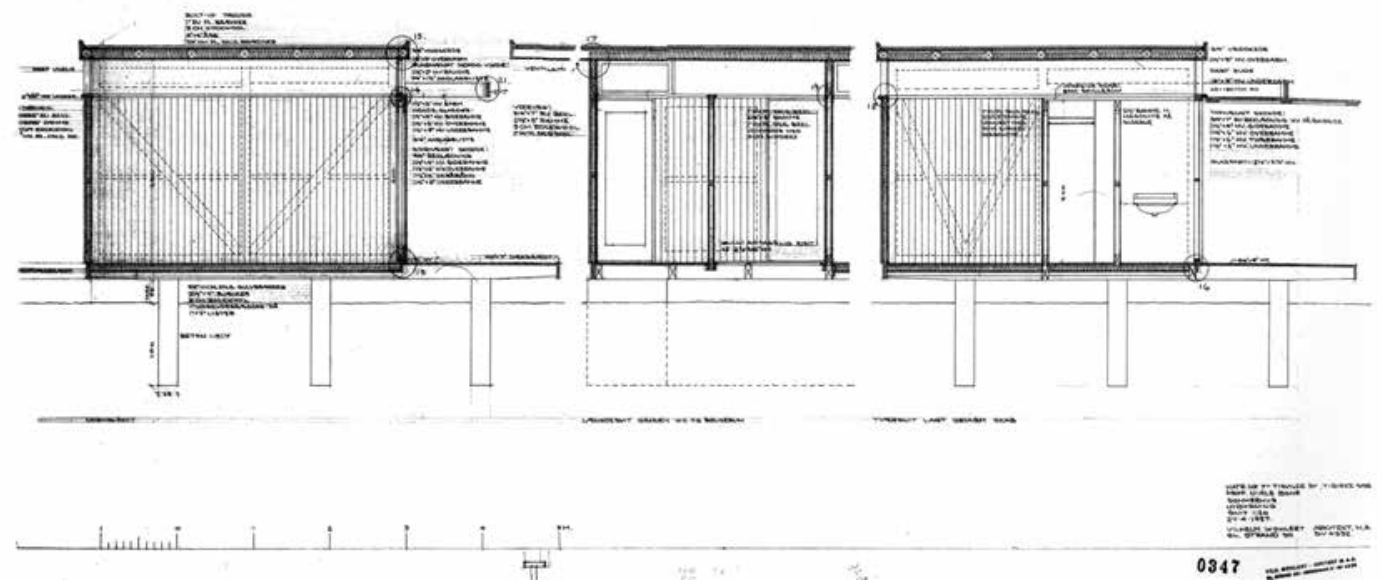




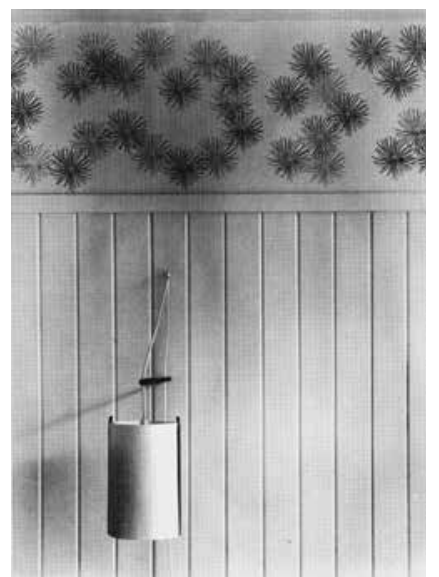

[15]

[15] Imagen detalle de aplique y friso decorado con motivos de ramas de pino, en el interior del pabellón Niels Bohr. Fotografía de Jesper Høm. MONIES, F., Træ Og Arkitektur. Copent og Arkitektens Forlag, 1958, p. 75

[16] Imagen interior de dormitorios del pabellón Niels Bohr desde el bosque. Fotografía de Jesper Høm. PARDEY, J.,et al., Louisiana and Beyond: The Work of Vilhelm Wohlert. Hellerup (Dinamarca): Blondal, 2007, p. 20.

[17] Vistas al jardín del palacio Imperial de la Katsura desde el pabellón de té Shoiken. YOSHIDA, T, Das Japanische Wohnhaus. Berlin: Verlag Ernst Wasmuth, 1935, p.165

[18] Imagen de la fachada sur del pabellón Niels Bohr en un mes de verano. Fotografía de Jesper Høm. MONIES, F., Træ Og Arkitektur. Copenhage: Træbranchernes oplysningsråd og Arkitektens Forlag, 1958, p. 25

[19] Imagen de un dormitorio del pabellón Niels Bohr de esquina. Fotografía de Jesper Høm. MONIES, F., Træ Og Arkitektur. Copenhage: Træbranchernes oplysningsråd og Arkitekternes Forlag, 1958, p. 70.

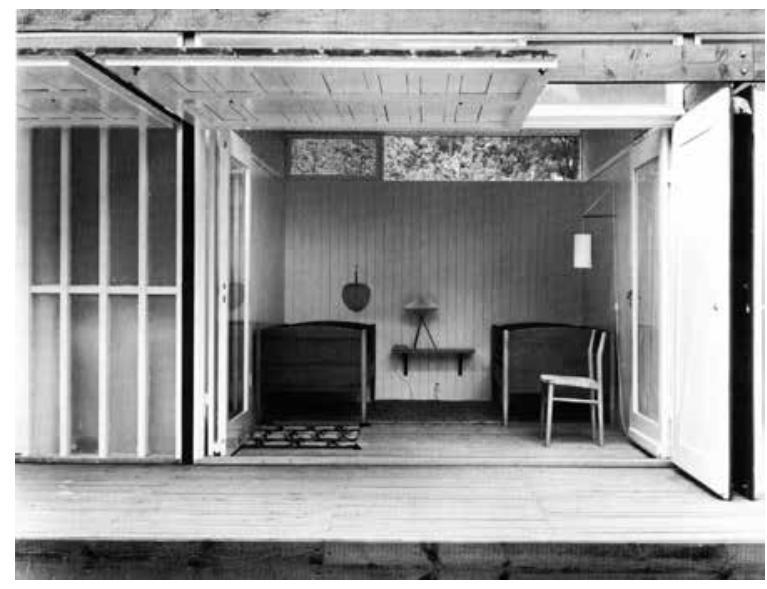

[16]

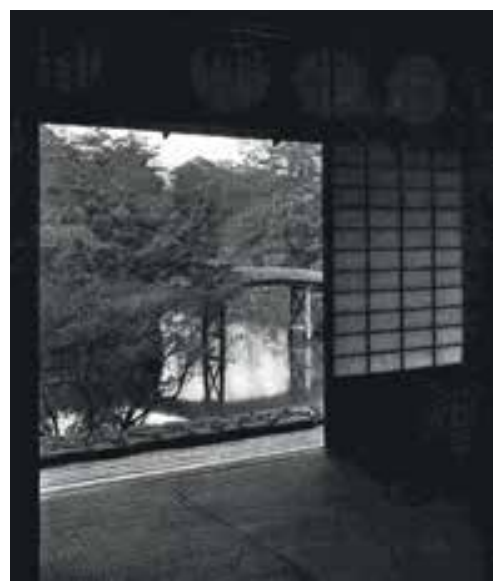

[17]

móviles, la caja que conforma el edificio se transforma abriéndose por compartimentos, como una fina pieza de ebanistería. Concebida como un lugar estacional, se puede cerrar a lo largo de los fríos inviernos daneses para, llegada la primavera, desplegarse parcialmente, hasta abrirse por completo durante el verano; es entonces cuando se establece una conexión entre el interior y el bosque de alrededor. Abierta, es como si el misterioso volumen, de tablas oscuras de madera aserradas en bruto, revelara el refinamiento de su interior, de madera blanca y acabado terso y suave, mostrando un gran contraste. Esta revelación aumenta la sensación de que el pabellón es un mueble de gran escala, una exquisita pieza de mobiliario hermosamente creada a mano, donde todo está pensado, cada elemento está medido y ajustado, encajando a la perfección. [18]

Liberado todo el ancho de las habitaciones, su espacio se extiende al exterior uniéndose al espacio de la terraza y al claro, integrándose con la naturaleza [19]. El efecto de la cubierta plana, y las contraventanas elevadas paralelas a ella, obliga a relacionarse con el entorno horizontalmente, acentuando esa expansividad del espacio, que se abre al medioambiente. "La casa teñida de negro abre su blanco interior al sol y al bosque con su maravilloso olor a pino. Las habitaciones y la terraza forman una unidad"23. El solado de tablones de pino sin tratar, colocados en paralelo a la fachada, tanto dentro como en la terraza, colabora para conseguir este efecto de prolongación del interior hacia el exterior. Solamente un travesaño colocado sobre el suelo interrumpe esta continuidad, donde cierran todas las capas; está para fijarlas y por estanqueidad; pero también para obligar a descalzarse al entrar de acuerdo a la tradición danesa, y casualmente también japonesa, manteniendo la suciedad fuera. Un escalón marca donde hay que quitarse los zapatos en la casa Japonesa y el pabellón de té, es una acto de purificación, dejando al suciedad fuera, procedente de la filosofía Shinto de la limpieza. Un travesaño en el suelo ya se utilizaba en el palacio de la Katsura en el camino del acceso de piedra, para obligar a descalzarse.

El aspecto del edificio está sujeto a constantes cambios: según la hora del día, la estación del año, el tiempo atmosférico e, incluso, la ubicación del observador [20] [21] [22] [23]. Este sistema flexible de capas móviles, además, permite a los huéspedes adaptarlo a sus preferencias, asegurándoles el confort a lo largo del año. Desde el interior ofrece niveles de percepción del bosque diferentes, donde la belleza penetra gradualmente, deleitando todos los sentidos ${ }^{24}$, al igual que en la casa japonesa. Se perciben los aromas del bosque, de la tierra, de las tablas de madera, se siente el sonido del viento, de la lluvia cuando cae sobre la delgada cubierta plana, etc.

Los primeros esquemas del proyecto muestran ya la elegante economía encontrada en el modo natura ${ }^{25}$ del uso de los materiales y capturan la esencia de un edificio modular en el que había

23 "The black-stained house opens its white-painted interior to the sun and to the wood with the lovely smell of pine. Rooms and sundeck form a whole". (WOHLERT, V., 1987, p 10).

${ }^{24}$ La arquitectura japonesa está hecha para percibirla con todos los sentidos. El filósofo e historiador japonés Tetsuro Watsuji (18891960) usaba el término fudo, (que significa viento y tierra) como un término para un medio cultural socio-histórico para el cual las experiencias de los fenómenos atmosféricos eran ingredientes esenciales (WATSUJI, T Culture and climate: a Philosophical Study". Tokio: Hokuseido Press, 1971, p. 201, citado por ANDERSSON, À., 2012. p. 88 Londres).

[18]

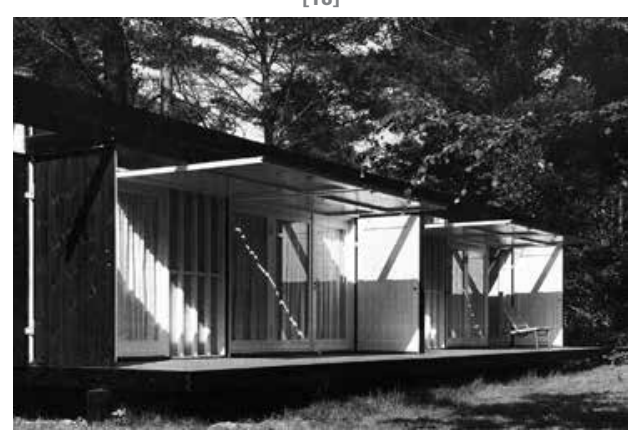

[19]

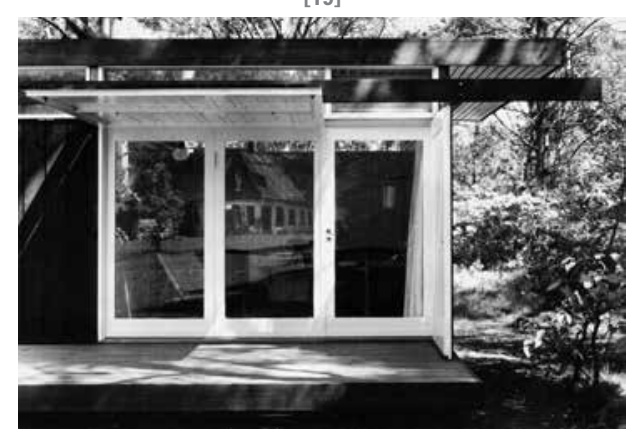


[20]
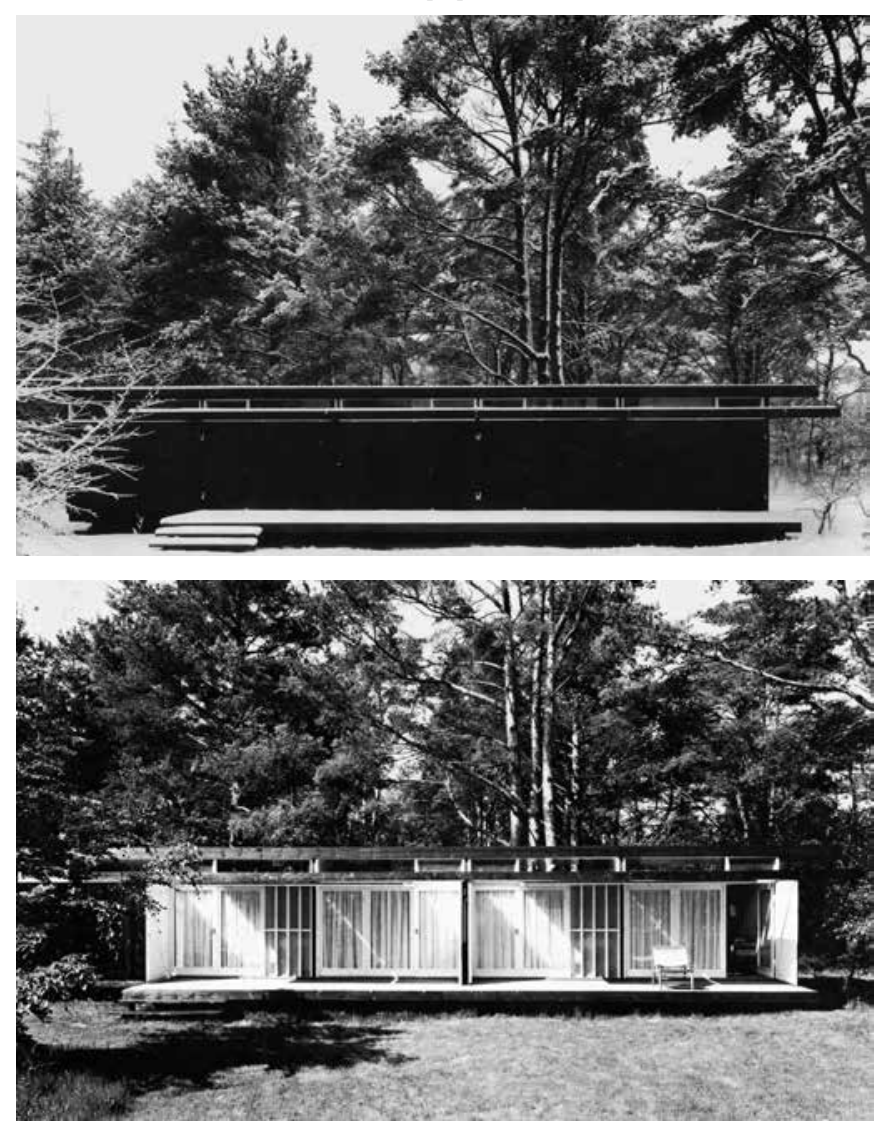

[22]
[21]
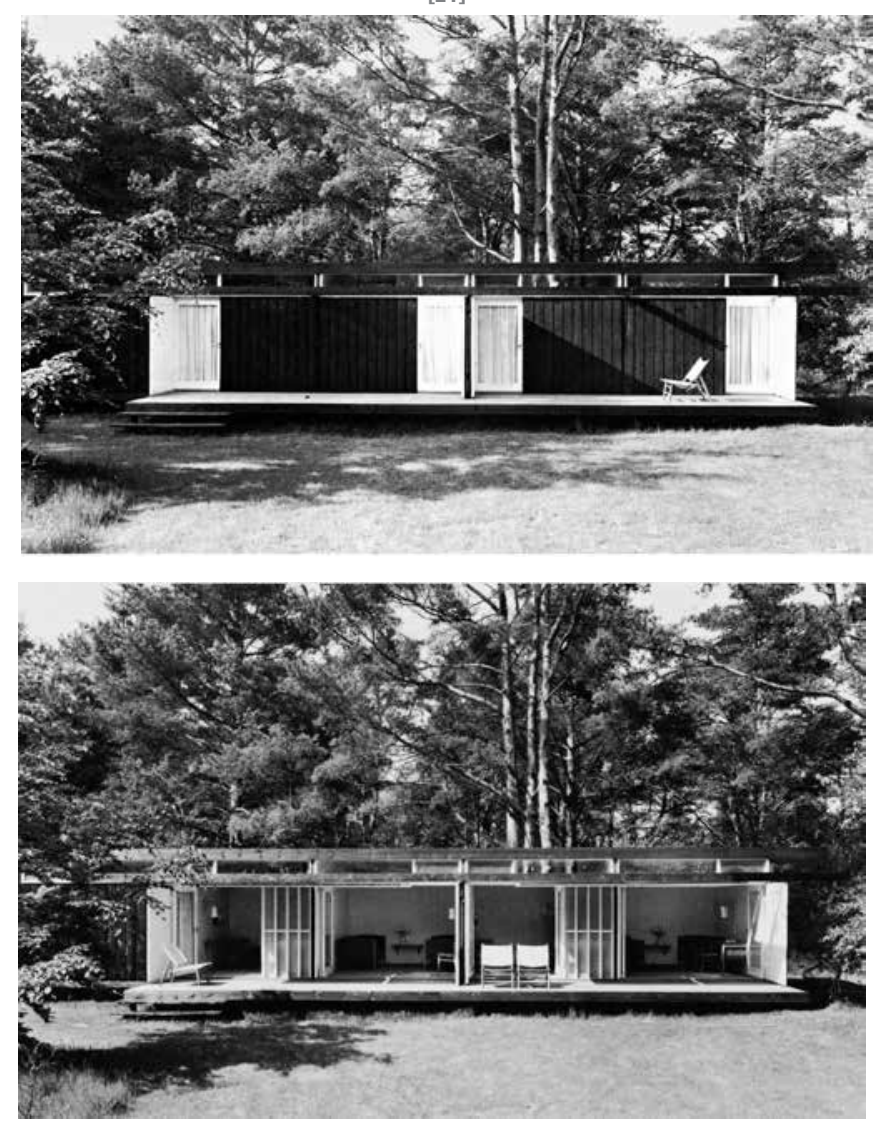

[23] una devoción por hacer vida en la terraza, además de por una integración total del edificio, su forma y sus detalles ${ }^{26}$ [24]. La terraza podría recordar a la casa Farnsworth, obra de Ludwig Mies van de Rohe (1886-1969), pero Wohlert y Mogens Prip-Buus ${ }^{27}$ insistían en que no tenía nada que ver, la arquitectura danesa, aclaraban, consistía en una forma diferente de pensar, aunque sí podríamos relacionarlo con la abstracción característica de Mies. El arquitecto explicaba: "Mi trabajo estaba todavía muy influenciado por el tiempo que pasé en California, donde mi familia y yo pasamos un par de años. Las casas de la bahía de San Francisco, que me enseñaron mis colegas de la Escuela de Arquitectura de Berkeley, me impresionaron por su cercana asociación con la exuberante naturaleza de alrededor que las mejoraba y hacía interesantes" 28 .

La arquitectura de Frank Lloyd Wright (1867-1959), la del "Area de la Bahía" y sus conexiones con Japón sí tienen relevancia. El entramado modular además de inspirarse en la tradición vernácula de construcción en madera, ${ }^{29}$ traza una línea con las edificaciones de madera del área de San Francisco de Bernard Maybeck (1862-1957), donde Wohlert estuvo invitado dos años como profesor, al principio de los 50 . La inspiración de la cultura japonesa venía de publicacio-

[24]
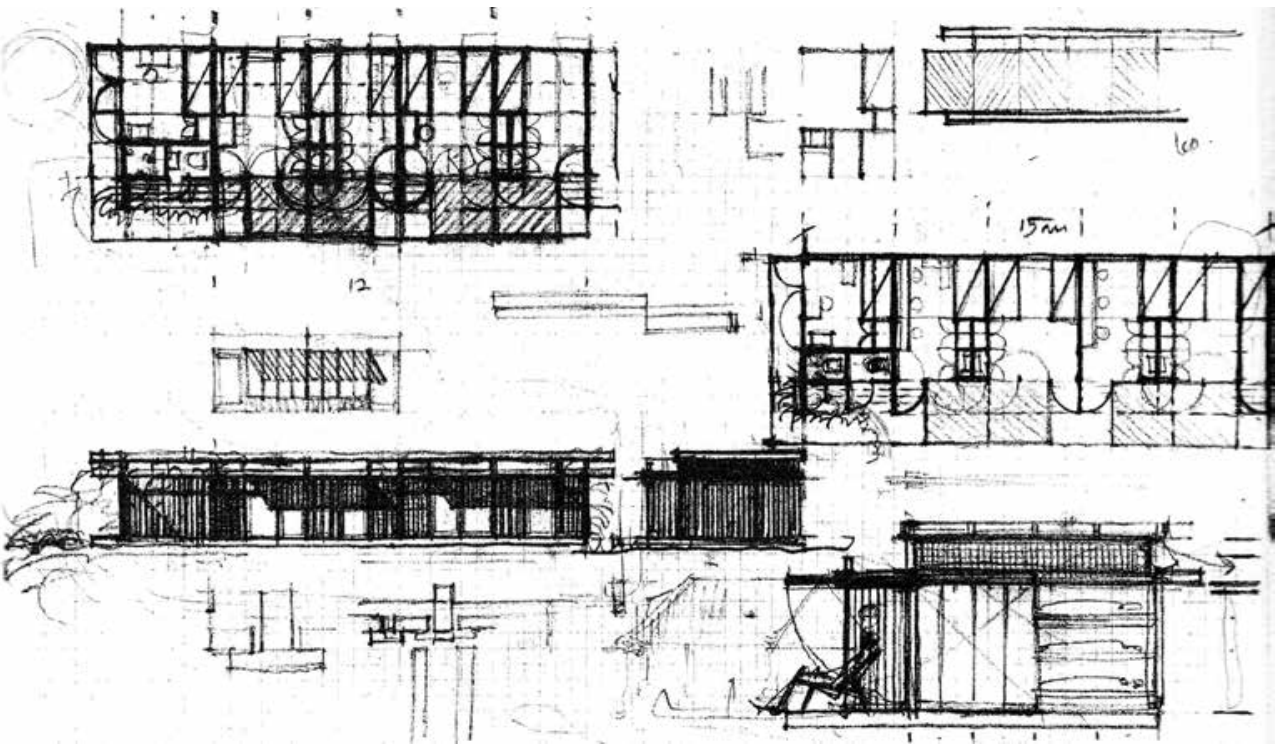

25 En el sentido de hecho con verdad, sin artificio, conforme a sus cualidades.

${ }^{\mathbf{2 6}}$ Los planos y secciones del proyecto se dibujaron escala 1:1 e ilustran cada tablero y pieza de la trama.

${ }^{27}$ Su ayudante y alumno más aventajado, el responsable del laborioso trabajo de coordinar el ancho de las paredes con el ancho de los tableros, para que todo el edificio fuera construido con piezas enteras.

28 "My work was still very much influenced by my time in California where my family and I had spent a couple of years. The houses by the bay of San Francisco, shown to me by my colleagues at the School of Architecture at Berkeley, impressed me by their close association with their luxuriant nature around them which enhanced them and made them significant." (WOHLERT, V., 2007. p.16).

[20] [21] [22] [23] Fotografias de cambios de imagen del pabellón Niels Bohr según diferentes situaciones. Colección de Aage Lund Jensen. SHERIDAN, M., Mesterværker, Copenhage: Strandberg Publishing, 2011, [24] Croquis a lápiz de los primeros planel pabellón Niels Bohr. Autor Vilhelm Wohlert. SHERIDAN, M Mesterværker, Enfamiliehuset i Dansk Arki-
tekturs Guldalder. Copenhage: Strandberg Publishing, 2011, p.186.

[25] Imagen lateral, tomada desde el oeste, de las contraventanas elevadas y terraza del pabellón Niels Bohr cuando está completamente abierto. Fotografia de Jesper Høm. MONIES, F., Træ Og Arkitektur. Copenhage Træbranchernes oplysningsråd og Arkitektektens Forlag, 1958, p. 71

[26] Imagen de un shitomido elevado en la residencia de Sakano, Japón. KUMA, K. et al Kyokai: A Japanese Technique for Articulating 2010, p. 24. Cortesia de Tankosha Publishing 
${ }^{29}$ La estructura de los edificios de los danevirke corresponde a un sistema constructivo llamado Stav, muy primitivo, y que se desarrolló con posterioridad a lo largo de la Edad Me dia, en casi toda Europa, alcanzando un grado de tecnología que permitió la construcción de grandes edificios de madera. Se componía de muros formados por tablones verticales y de un techo sostenido generalmente por cuatro grandes columnas de madera emplazadas en el medio de la nave-tiene, en contraposición a sistema Laft de troncos horizontales, que se desarrolló posteriormente en el norte de Europa. En el sistema Stav la libertad de la planta es mayor y permite toda clase de formas: circulares, elipticas, cuadradas, etcétera.

${ }^{30}$ Los libros Japanese homes and their surroundings (1886), de Edward Morse (directo de la Academia de las Ciencias de Boston), The book of tea (1906), de Kakuzo Okakura, y, especialmente, Das Japanische Wohnhaus (1935), de Tetsuro Yoshida, publicado en Berlin, y Des japanische haus und sein leben (La casa y la vida japonesas), de Bruno Taut, publicado en inglés en 1937.

${ }^{31}$ El primer pabellón de té en Europa se construyó en Estocolmo, el "Zui Ki Tei" (Hogar de la luz prometedora), en 1935, en los jardines del Museo Etnográfico. Había sido construido en Japón y desmontado y transportado por barco para su montaje en Suecia. Fue una donación de la sociedad sueco-japonesa que, construido por artesanos japoneses, se convirtió en lugar de peregrinación. Fue destruido por un incendio en octubre de 1969 y sustituido más tarde por otro pabellón. Una de las primeras fuerzas para que se edificara fue Ida Trotzig (1864-1943), escritora sueca, etnógrafa y especialista en cultura japonesa.

${ }^{32}$ Lloyd Wright y los hermanos Charles y Henry Greene (1868-1957 y 1870-1954) tuvieron la oportunidad de visitar el pabellón japonés "Ho-o-den" o "Phoenix Pavillion" expuesto en la "Chicago World's Columbia exhibition" en 1893 (fue donado por el gobierno japonés ansioso por mostrar al mundo su poder, modernización y logros, tras la clausura de la feria). Consistía en tres estructuras unidas por una pasarela cubierta dando forma en planta al ave Fénix. Los elementos que lo componian habian sido diseñados y elaborados en Japón y transportados junto con carpinteros, canteros y jardineros, en barco de vapor $y$ tren. El edificio era completamente diferente a los demás pabellones de la exposición, que eran pesados, en su mayoría construidos en un imponente estilo Greco-Romano, entonces muy popular en Estados Unidos. Tenía una gran cubierta que lanzaba sombras sobre espacios transparentes, sin paredes, que se desplegaban. Además, su interior se abría al jardín, también de diseño japonés.

${ }^{33}$ La supresión de la barandilla es un recurso que ya se utilizaba en la arquitectura de la Ka sura en la terraza de la luna, esto, unido a la eliminación de los pilares del porche japonés, favorece la continuidad del espacio y mejora la integración en la naturaleza.

${ }^{34}$ Los Greene visitando el "Ho-o-den" pudieron ver, probablemente por primera vez, un trabajo de arquitectura japonesa, conociendo así la tradición del uso de la madera de Japón. Sintieron gran afinidad por el cuidadoso tallado de la madera y su construcción expuesta. También fueron testigos del modo en que se diseñaba el ajardinamiento e integraba sutilmente con lo que le rodeaba. De todo ello se hacian eco sus últimos trabajos, algunos de ellos construidos por artesanos japoneses. El más destacado era la "Casa Gamble" (1908), que ejemplarizaba el microcosmos que se creaba en sus obras, y la idea de belleza asociada a lo funcional. En ella, cada esquina estaba estudiada, cada línea tenida en consideración, y todos los muebles diseñados y colocados adecuadamente.

35 Por ejemplo carece del espacio continuo entre las estancias, en su interior la estructura no está expuesta y la cubierta plana carece de la gran presencia oriental.
[25]

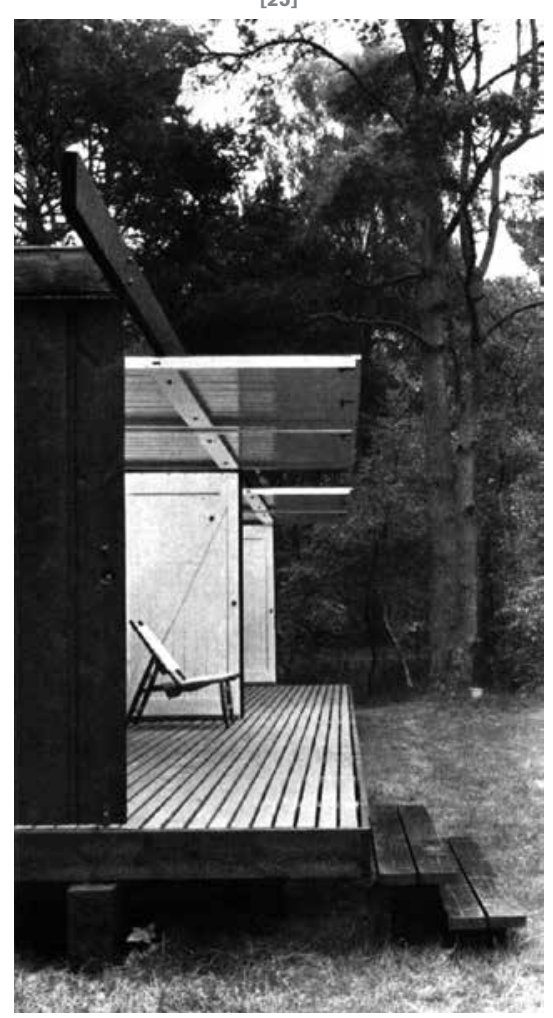

[25]

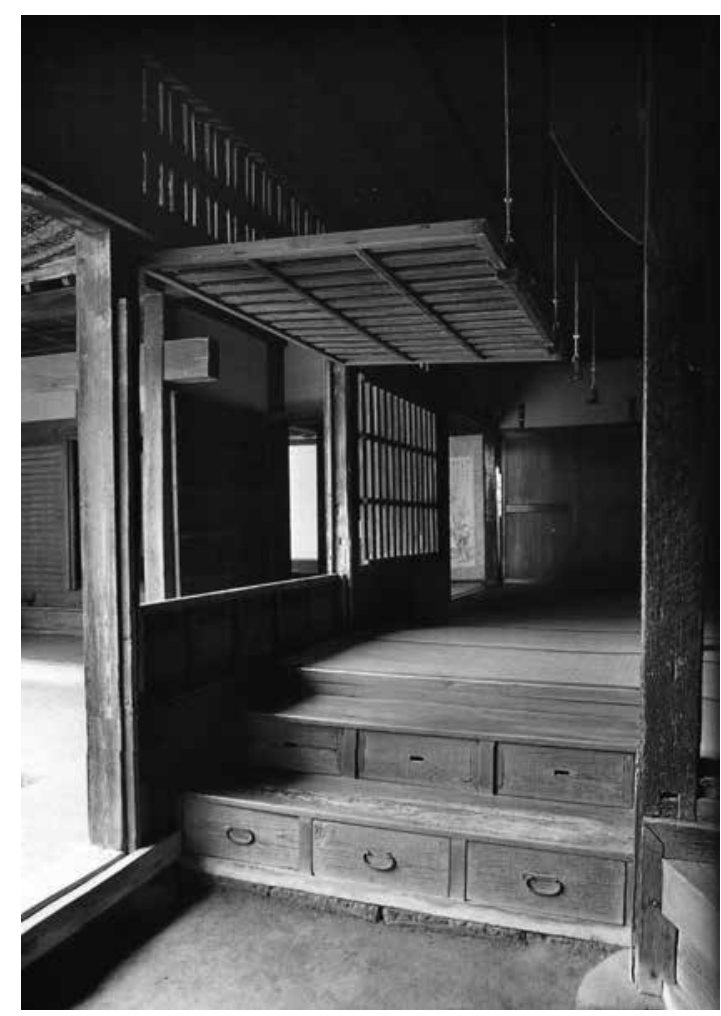

[26] nes especializadas ${ }^{30}$, del pabellón de té Zui-ki-tei de Estocolmo ${ }^{31}$ e indirectamente a través de la obra de Wright y los hermanos Charles y Henry Greene (1868-1957) (1870-1954) ${ }^{32}$.

La terraza evoca al porche o engawa nipón, el cual facilita la relación con la naturaleza, y constituye un lugar para la vida, el reposo, la reflexión y, en ocasiones, la observación de la luna ${ }^{33} ; \mathrm{y}$, en menor medida, a la obra de los Greene ${ }^{34}$, de clara inspiración japonesa, como la casa Gamble 1908, donde las terrazas, resultado del estudio de la lógica del lugar y la vocación por la relación con la naturaleza, son zonas intermedias para experimentar el contacto exterior y descansar. Ya hemos visto que la casa de invitados, aunque carece de muchas características de la casa tradicional japonesa, ${ }^{35}$ recuerda a ella. Las grandes contraventanas se han inspirado en los shitomido nipones, cumplen la misma función de cerrar la casa, proteger de la luz y de las inclemencias del tiempo ${ }^{36}$. Cuando están suspendidas en horizontal, a modo de nok ${ }^{37}$, generan bajo ellas espacio, que tan solo tiene $2.008 \mathrm{~mm}$ de altura libre; invitan al recogimiento y a sentarse a disfrutar, posición desde la cual la altura no resulta baja al igual que en los porches japoneses donde se sientan sobre las rodillas en el suelo. Para un campesino japonés sentarse en el tatami era como sentarse en la hierba, arraigándose a la tierra. [25] [26]

Bruno Taut (1880-1938), en la descripción que hacía sobre la casa japonesa ${ }^{38}$, destacaba frente a su aspecto material, su vida; como un teatro al aire libre, cuyo fondo es la naturaleza que se veía a través de la pared abierta, donde se podía percibir el encanto de la vida doméstica y la conducta natural de las personas tumbadas, sentadas o en cuclillas, donde la proporción entre el hombre y la casa estaban en sintonía. Así Wohlert imaginaba y dibujaba la vida del pabellón, cuyo carácter horizontal, introducido por sus líneas principales, prevalece como telón de fondo. [27]

A pesar de la separación del terreno y su geometría ortogonal de líneas rectas, el pabellón tiene el carácter sensible de un organismo vivo, como una flor que cierra y abre sus pétalos de acuerdo a los cambios de estación, de la luz del día o de la temperatura. Guarda una fuerte relación con el mundo vegetal, no solo por la conexión con la naturaleza que lo rodea y el material con el que se construye, todo de madera. La madera es un material que envejece más rápidamente que otros, después de un tiempo retorna al sistema biológico, este envejecimiento nos habla de la muerte. En Japón se valoran los edificios viejos porque están más cerca de la muerte, la madera envejecida no es bella por ser hermosa, sino porque ha recorrido una experiencia importante. Es especialmente bella porque se encuentra próxima a la muerte, y por tanto próxima a fundirse con la muerte. Pero la juventud del material también tiene su belleza: el tatami nuevo que aún huele y el fresco aroma de la madera usada en la construcción. Este tipo de sensibilidades también las encontramos en la arquitectura del pabellón. Casi podría tratarse de una expresión del arte floral japonés Ikebana, definido por Sōfu Teshigahara (1900-1979) como el 
arte del espacio ${ }^{39}$. En la casa de invitados el espacio entre contraventanas y puertas cobra vida, un espacio que proyecta tensión y transmite una misteriosa energía. El Ikebana es algo vivo que expresa, a diferencia de otros artes florales, la emoción del material, la tercera dimensión y el equilibrio asimétrico, características presentes en el pabellón, en el cual las variaciones de las contraventanas acentúan el efecto tridimensional, dándole a la fachada una gran profundidad y plasticidad, permitiendo la movilización del espacio. El filósofo y escritor francés Roland Barthes (1915-1980) habla del lkebana, como una producción de "circulación del aire, de la cual las flores, hojas, ramas,... son solo las paredes, los corredores, los deflectores ${ }^{\prime 40}$.

La inesperada falta de cierre, la circulación del aire y los elementos que le dan flexibilidad, crean un sugerente aire de libertad y fluidez. El aire pasa libremente, los copos de nieve o las hojas de los arboles entran conducidos por el viento, los pájaros, las mariposas pueden volar dentro de las habitaciones, recordándonos la idea formulada por primera vez por Heráclito de que el mundo es un estado de flujos, cuando dijo "ta panta rhei", (todo fluye) ${ }^{41}$. Así, Wohlert establece en su obra una arquitectura de flujo, que en esta queda constreñido por las divisiones entre habitaciones, pero que en obras sucesivas será más evolucionada y libre.

Wright introdujo el espacio sin límites como concepto revolucionario de espacio interior, como un medio continuo con aire en su interior, fluyendo por todas partes, fuera y dentro, conectando todo y extendiéndose hasta el infinito. Como en las casas de la pradera, que se extiende hacia

[27]
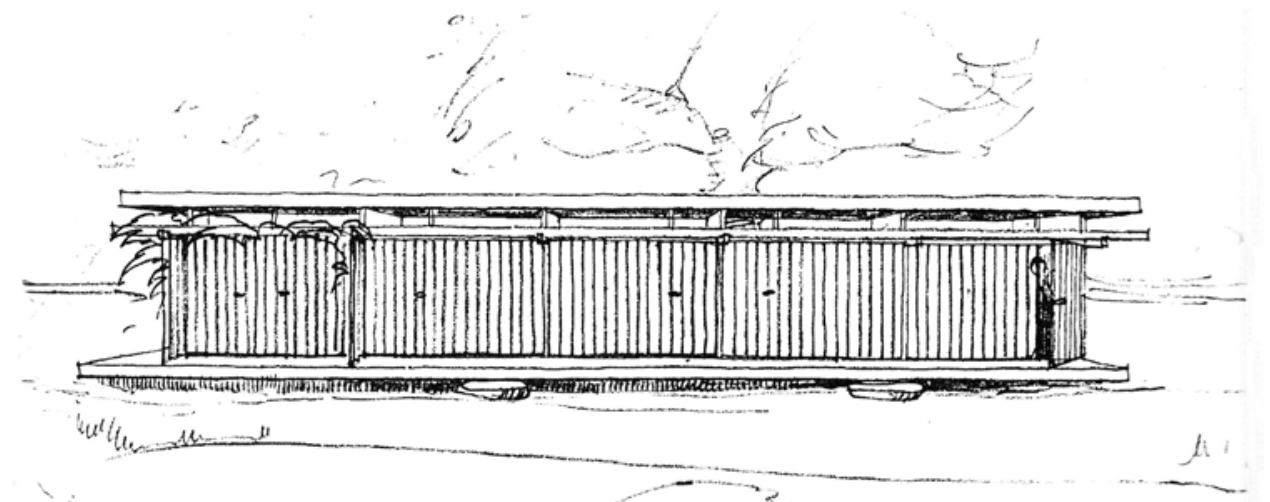

Facade om vinteren.

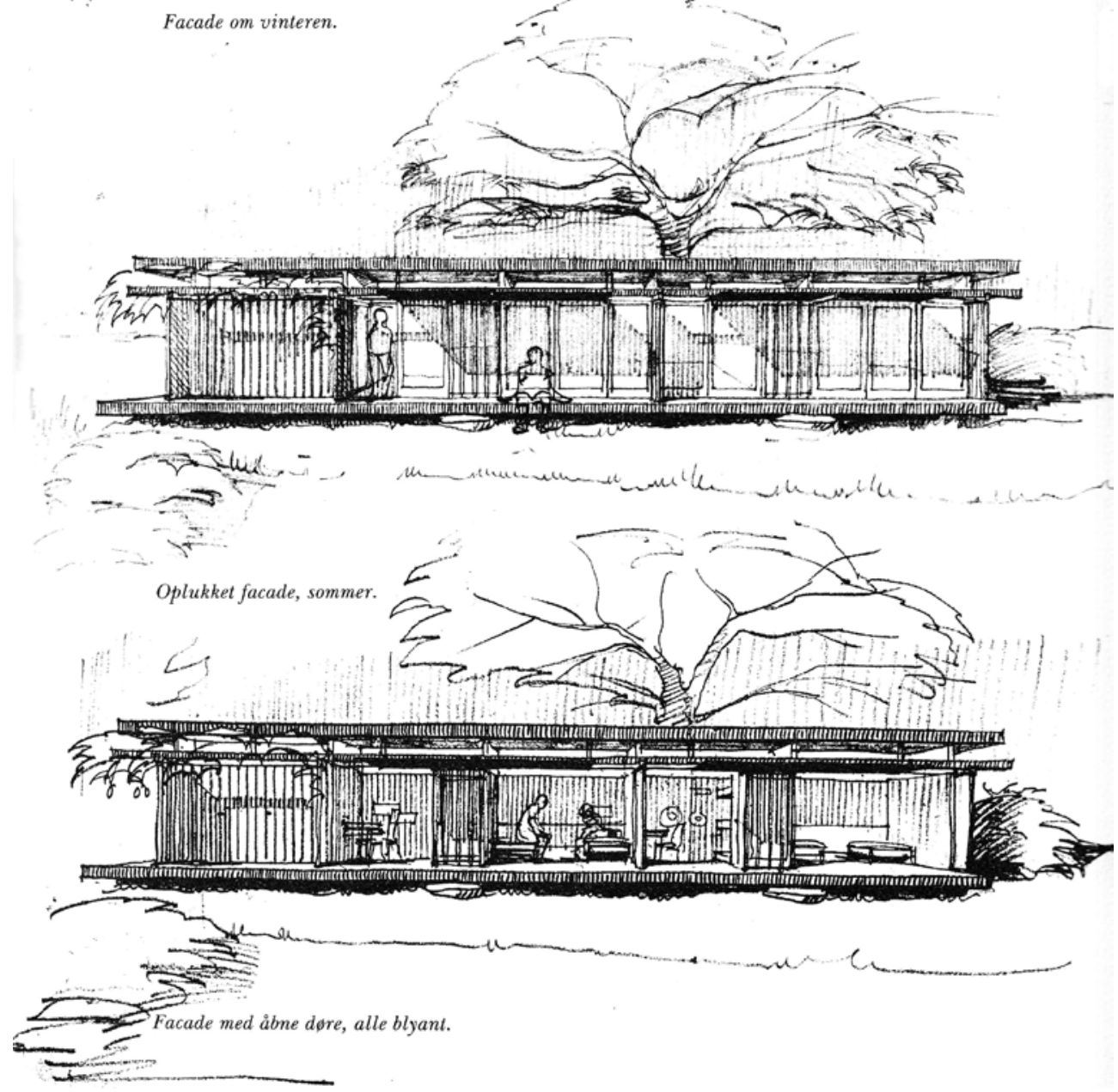

${ }^{36}$ El shitomido es una contraventana abatida en la parte alta que se usaba en la arquitectura tradicional japonesa para proteger el interior del viento y de la lluvia antes de la invención de la puerta corredera de madera. Consiste en un entramado de madera, al cual se unen tableros, que protege de la luz y de las inclemencias del tiempo. La mayoría de los shitomido consisten en un conjunto de dos paneles divididos horizontalmente, la parte baja del panel se mantiene vertical y la parte alta es la que está unida al edificio mediante bisagras, de manera que pueden a batirse tanto hacia el interior como hacia el exterior para suministrar luz y ventilación. En el Palacio Imperial de Kioto se utilizan para cerrar el vestibulo.

${ }^{37}$ Noki es el alero que protege las paredes externas en la arquitectura tradicional japonesa.

38 Tras vivir en Japón una larga temporada en compañia de su esposa, escribió el libro de enorme trascendencia Des japanische haus und sein leben (La casa y la vida japonesas).

${ }^{39}$ Es el fundador de la escuela Sōgetsu en 1927.

40 "(...) circulation of air, of which flowers, leaves, branches... are only the walls, the corridors, the baffles." BARTHES, R. Empire of Signs. NY: 2000, pp. 44-45, citado por ANDERSSON, Å., Londres: 2012, pp. 89-90.

41 Citado por BALLANTYNE, A. et al., Londres: 2012, p. 1.

42 En ella utiliza un ladrillo como expresión moderna de la construcción con un único material, exactamente el mismo de la iglesia de Grundtvig de J.Klint, que modula todo el edificio. (En conversaciones con Jan Utzon, en la casa de Hellebæk en septiembre de 2013).

${ }^{43}$ A mediados de 1920 Breuer buscaba en la imagen externa de sus casas la misma estética de la ligereza a que aspiraba en el desarrollo de sus sillas tubo de acero. Con una diferencia decisiva generada por la naturaleza distinta de cada tarea: mientras que las sillas, butacas... forman volúmenes "abiertos", perfilados por la estructura de tubo de acero como "lineas en el espacio", la casa necesita una envoltura exterior protectora. En la casa de Metal propone como solución el negar la separación espacial entre armazón portante y las planchas apoyadas en él. Es decir, evitar a toda costa los pilares en medio del espacio, llega a negar el sistema tectónico visible a favor de la acentuación de "la superficie absoluta". Así, el muro concebido como la estructura más ligera y rígida posible de un volumen, recuerda un poco a las paredes de un mueble caja. La casa Chamberlain Cottage (1940) en Wayland, Massachusetts, pequeña pero importante, es toda de madera, aparece ya el voladizo, el balloon frame, las habitaciones ya están reguladas por un módulo $1: 2$ y se parece mucho a sus muebles. En sus construcciones de madera surgen rayas automáticamente en el recubrimiento de listones de madera, su disposición vertical, a veces horizontal, incluso diagonal, indica un manejo consciente de la estructura y al mismo tiempo pone de manifiesto su función estática. Sus plantas están reguladas por un módulo de proporción 1:2, y el conjunto se caracteriza por su sobriedad y elegancia. Usa con maestría la combinación de materiales generando los más diversos contrastes: entre dos colores, entre claro y oscuro, áspero y liso, duro y suave, natural y artificial. Las texturas naturales contenidas en el propio material representaban para él un sustituto tanto del ornato artificial como de la estructura superficial resultante del manejo y elaboración de materiales de construcción.

44 Por ello la estructura no se detecta y los marcos de las ventanas se conciben detrás de las paredes interiores. 


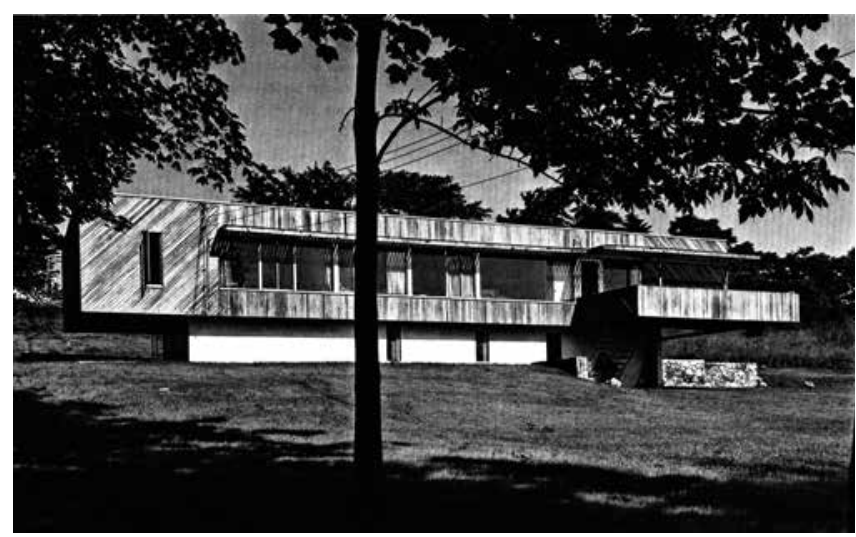

[28]

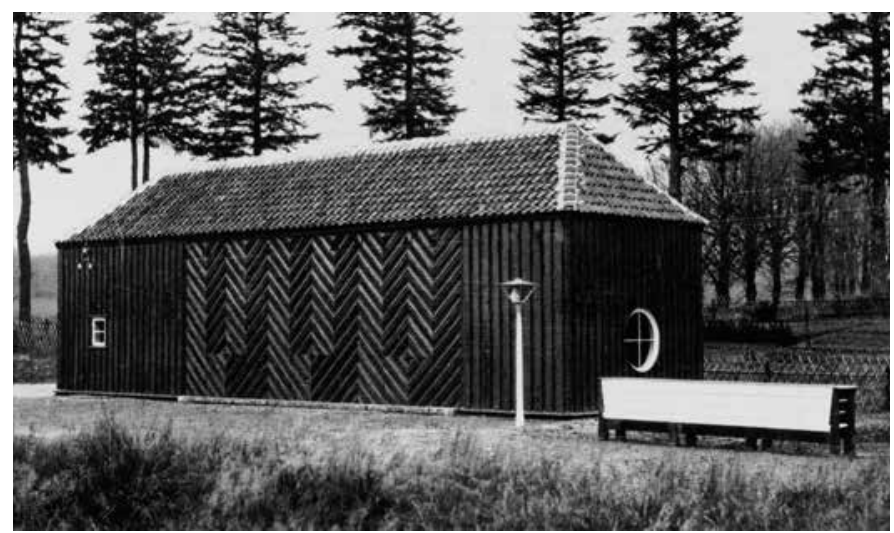

[29]
45 "Langhaus" es el más sencillo de los tipos de sus viviendas en América que el propio Breuer clasifica, en este aparece el cuerpo dulo de proporción $1: 2$ regula la planta y el edificio es tratado como un mueble también. Uno de los más conocidos ejemplos es la casa que construyó para su familia y él (1947-48) en New Canaan, Marcel Breuer II.

${ }^{46}$ Kay Fisker fue profesor de Wohlert y la figura central del desarrollo del Funcionalismo danés. Como editor de la revista Arkitekten de 1919-1926, jugó un papel importante en los debates del periodo promoviendo el flujo constante de los escritos y comentarios de Jensen Klint. Empezó de profesor en la Escuela de Arquitectura como ayudante del Edvard Thomsen, catedrático. Después, como docen te en el área de construcción de viviendas, fue defensor de la figura de Gunnar Asplund en Dinamarca, invitándole a la Escuela y programando viajes con sus estudiantes a su obras en Estocolmo. En 1936, como catedrático del departamento de Arte de los Edificios, se convirtió en la figura dominante de la Escuela durante más de un cuarto de siglo. Combinó sus ideas, a las que llamaba escuela de Klint, con las ideas del funcionalismo alemán, para realizar edificios sencillos de ladrillo inspirados en la tradición vernácula.

47 En 1915, junto con su compañero de clase Aage Rafn, ganó el concurso para la estación Christianshoj, de la línea de Gudhjem, en la isla de Bornholm. Después trabajaron temporalmente en el estudio de Asplund y Lewerentz. Hacia 1920 proliferaron los concursos de casas de vacaciones que estimulaban la imaginación y experimentación, por su libertad de programa. Fisker realizó una serie de proyectos de planta rectangular entre 1916 y 1918

${ }^{48}$ Texturas: habla del poder del acabado del material. Reclama que cada material debe mostrarse con la textura que le sea fiel, que no lo desvirtúe ni le prive de su esencia, que sus partes no apaguen el todo al que pertenecen. Un ejemplo es el caso de la madera, al no cubrirse por ningún barniz, huele, se toca, su textura otorga calidez y da un toque de naturaleza a los interiores nórdicos.

49 Contrastes: La escala y la proporción

aparecen como temas en la segunda confe rencia. El ritual del paso del exterior al interior debe también quedar sometido a una serie de consideraciones que permita mantener un tránsito equilibrado y natural. Los elementos compositivos quedan sometidos a la lógica de la proporción: el equilibrio de masas y de superficies. Habla de la relación del edificio con respecto al entorno donde está situado.

${ }^{50}$ Colores: reflexiona sobre el hecho de que un color aislado no es lo mismo que acompañado de otros.

51 Donde se describen los efectos perseguidos por los arquitectos de la época del Neoclasicismo nórdico, en un afán de integración de todas las artes, los oficios artesanos, de referencias del pasado y de otras culturas. Tuvieron gran relevancia ya que generaron una base con la que se comprometería el trabajo el paisaje, cuya planta estaba ordenada siguiendo una modulación con la proporción del tatami japonés. No sólo creó una arquitectura abierta, sino que se convirtió en un maestro de los límites. En el libro "The Book of tea" Okakura desvela como la esencia de la casa de té no está en el edificio en sí sino en el vacío generado en él. La idea de que la arquitectura no es un objeto material sino el espacio generado dentro de los objetos. Jørn Utzon ya plantea en su casa de Hellebæk (1952), un espacio sin límites, fundiendo por primera vez en Dinamarca la planta libre y la cubierta plana. Con la construcción de materiales sin tratar, rompe la caja tradicional del Funcionalismo danés, pero mantiene el contacto con la artesanía y uso de materiales tradicio$\mathrm{nal}^{42}$. [28]

Las referencias americanas también vienen de la arquitectura de Marcel Breuer (1902-1981) que fue de gran importancia para arquitectos daneses como Arne Jacobsen, Jørgen Bo y Erik Christian Sørensen, coetáneos de Wohlert ${ }^{43}$. En particular de sus viviendas unifamiliares, que se prestan particularmente bien a su ideal indivisible entre arquitectura e interiorismo, en las que logra gran sensación de bienestar e intimidad, y nunca son suntuosas. En su arquitectura es característico el extrapolar la construcción de muebles y utilizar la caja cerrada, en la que, al igual que Wohlert, quería enfatizar el espacio generado, en lugar de la estructura ${ }^{44}$. El pabellón de invitados recuerda a las casas alargadas de Breuer, tipo "Langhaus"51 [29]. Aunque los bocetos iniciales del pabellón desvelan que la orientación de las tablas del revestimiento exterior plantearon dudas, pues se tantea el colocarlas en diagonal, y podría relacionarse con las casas Breuer II en New Canaan (1948), o la "Caesar Cottage" en Connecticut (1952), donde ya disponía así las tablas, Wohlert tiene la referencia más cerca en la estación de ferrocarril de Bornholm (1916) diseñada por Kay Fisker (1893-1965) y Aage Rafn (1890-1953), que sin duda conoce ${ }^{46}{ }^{47}$. [30]

El pabellón representa un ejemplo importante de la tradición danesa; la sensibilidad hacia la naturaleza, la sensación de escala y la apreciación de la modestia y la moderación están unidas al sentido de funcionalidad y contextualidad, enraizadas en la cultura de la agricultura. Están presentes las tres conferencias del arquitecto danés Carl Petersen (1874-1923), "Texturas" $(1919)^{48}$, "Contrastes" (1920) ${ }^{49}$ y "Colores" $(1924)^{50}$, donde se describen los efectos perseguidos por los arquitectos de la época del Neoclasicismo nórdico, en un afán de integración de todas las artes, los oficios artesanos, de referencias del pasado y otras culturas, ${ }^{51}$ pero encarna la evolución de esta tradición y su renovación que está basada en la adaptación de influencias extranjeras como se ha explicado. Ya lo defendía el Manifiesto Acceptera (1931) "(...) Aceptad la realidad existente -solo así tendremos la posibilidad de poder controlarla, de superarla para poder cambiarla, y de crear una cultura que sea herramienta flexible para la vida- (...)"52.

El proyecto tiene un profundo sentido de unidad y encuentra la belleza del edificio en lo útil, unido a la proporción y armonía con el entorno y entre sus partes. Wohlert utiliza texturas que dan vigor y articulan las superficies, aprovecha el poder del acabado, estudia cada detalle, y valora la junta constructiva; ello, unido al ritmo de las líneas, prueba su vivo interés por los materiales, por su cualidad visual y plástica, y el efecto emocional que emanan [31] [32]. Usa la sensación como herramienta del proceso creativo, algo propio de los arquitectos del Modernismo nórdico, donde lo táctil y lo visible están íntimamente relacionados ${ }^{53}$. El arquitecto L. Mogens Lassen (1901 - 1987) ya señalaba "la habilidad de ver se deriva de la experiencia del tacto"54.

Por otro lado, supone un acercamiento hacia la modernidad, a la idea japonesa de que la casa no es un artefacto permanente, pesado y longevo, y nos aleja de la idea occidental "mi casa mi castillo"55. En 1931 el maestro sueco E. Gunnar Asplund (1906-1940) ${ }^{56}$ explicaba que el nuevo espacio arquitectónico de la modernidad: “(...) no busca encerrarse en sí mismo como una entidad independiente, sino abrirse con más o menos fuerza hacia el sol, la naturaleza, la humanidad 
y el movimiento"57. También explicaba que "La disolución (entendida como regeneración) y la flexibilidad del espacio, la liberación de la forma arquitectónica, la relación más próxima entre el interior y el exterior, todo ello, (...) parece indicar que nuestro concepto arquitectónico del espacio se está acercando a la hipótesis de Spengler: el espacio infinito"58. Protagoniza un ejemplo de la modernidad como refinamiento en la técnica de los límites y la idea de que la arquitectura no es un objeto material, sino el espacio generado en su interior ${ }^{59}$.

El Pabellón reinterpreta el arquetipo de la cabaña y representa uno de los modelos más sobresalientes de una serie de proyectos que se realizaron en Dinamarca a finales de los 50 , como versión moderna de arquitectura vernácula de madera teñida oscura y muros de ladrillo encalado, que tenía el mismo carácter y cualidades táctiles de las cabañas de pescadores o las granjas de muros con entramado de madera. Entre ellas hay ejemplos muy interesantes como la casa propia de Jørgen Bo 1954, en Hjortekaer, la casa Kokfelt 1956 en la misma localidad de Tisvilde, y una versión más evolucionada la casa Siesby 1959 en Lyngby ambas por Arne Jacobsen, las casas para su hermana y propia del arquitecto Klaus Ahlmann 1958 en Birkerød, Villa Orestrand 1953 en Vedbæk, la casa Tholstrups 1954 en Rungsted y la propia de las generaciones de arquitectos escandinavos sucesivas: Bryggman, Asplund, Lewerentz, Bentsen, Fisker, Henningsen, Aalto, Lauritzen, Jacobsen, Utzon y Wohlert, entre otros.

52 Manifesto Acceptera (Aceptad), escrito y firmado por 6 arquitectos suecos que promovian la aproximación al Funcionalismo: Gunnar Asplund, Wolter Gahn, Sven Markelius, Gregor Paulsson, Eskil Sundahl y Uno Åhrén.

53 "Cuando miramos, el ojo toca y, antes de ver un objeto, ya lo hemos tocado y hemos jugado su peso, su temperatura y su textura superficial. El ojo y la mano colaboran constantemente, el ojo lleva a la mano a grandes distancias y la mano informa al ojo en la escala intima. El tacto es la inconsciencia de la visión, y esta experiencia táctil oculta determina las cualidades sensoriales del objeto percibido". (PALLASMAA, J., 2011. p. 113).

54 (HARLANG, C., 2001. p. 52).

[30]

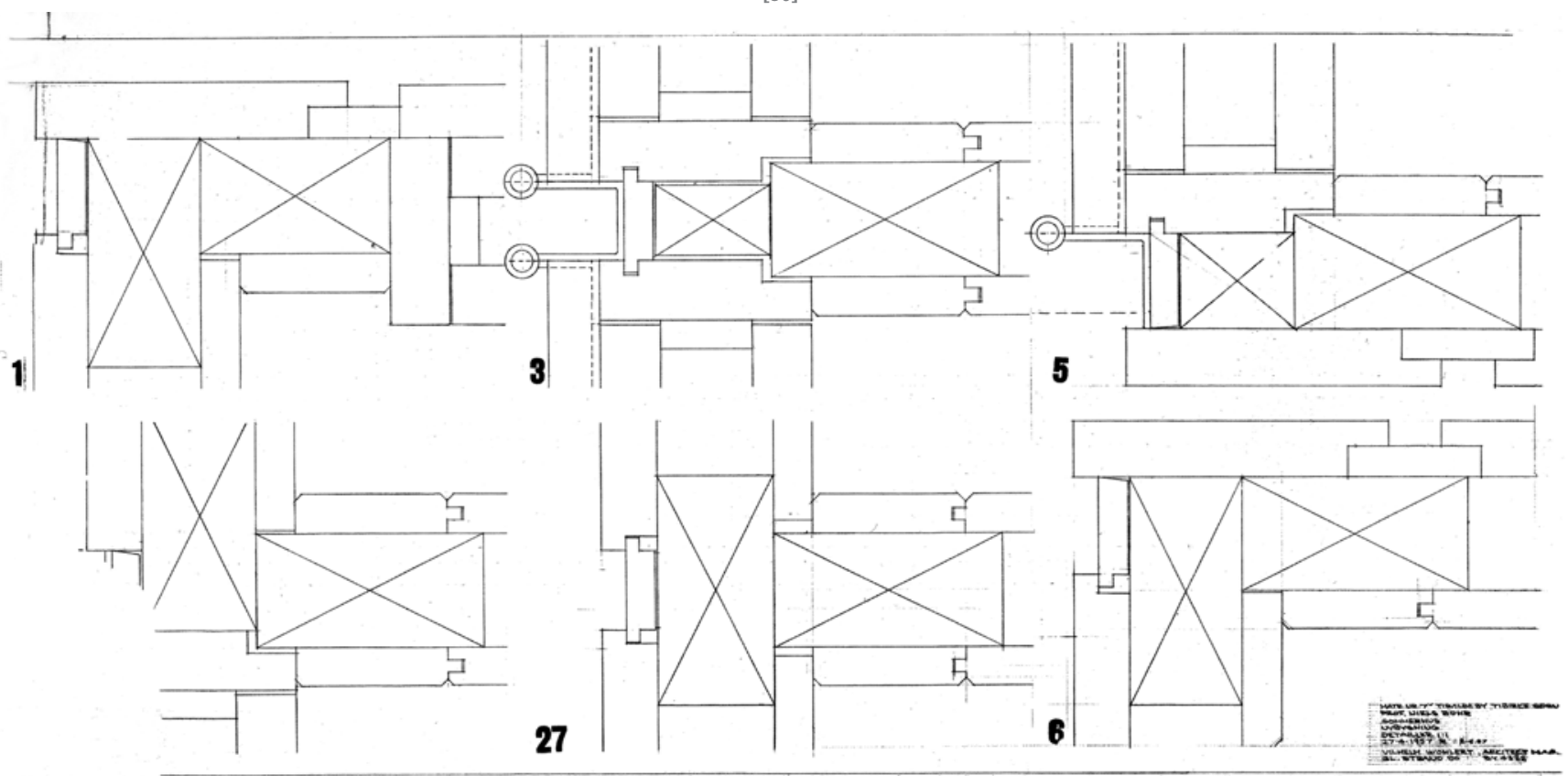

[31]

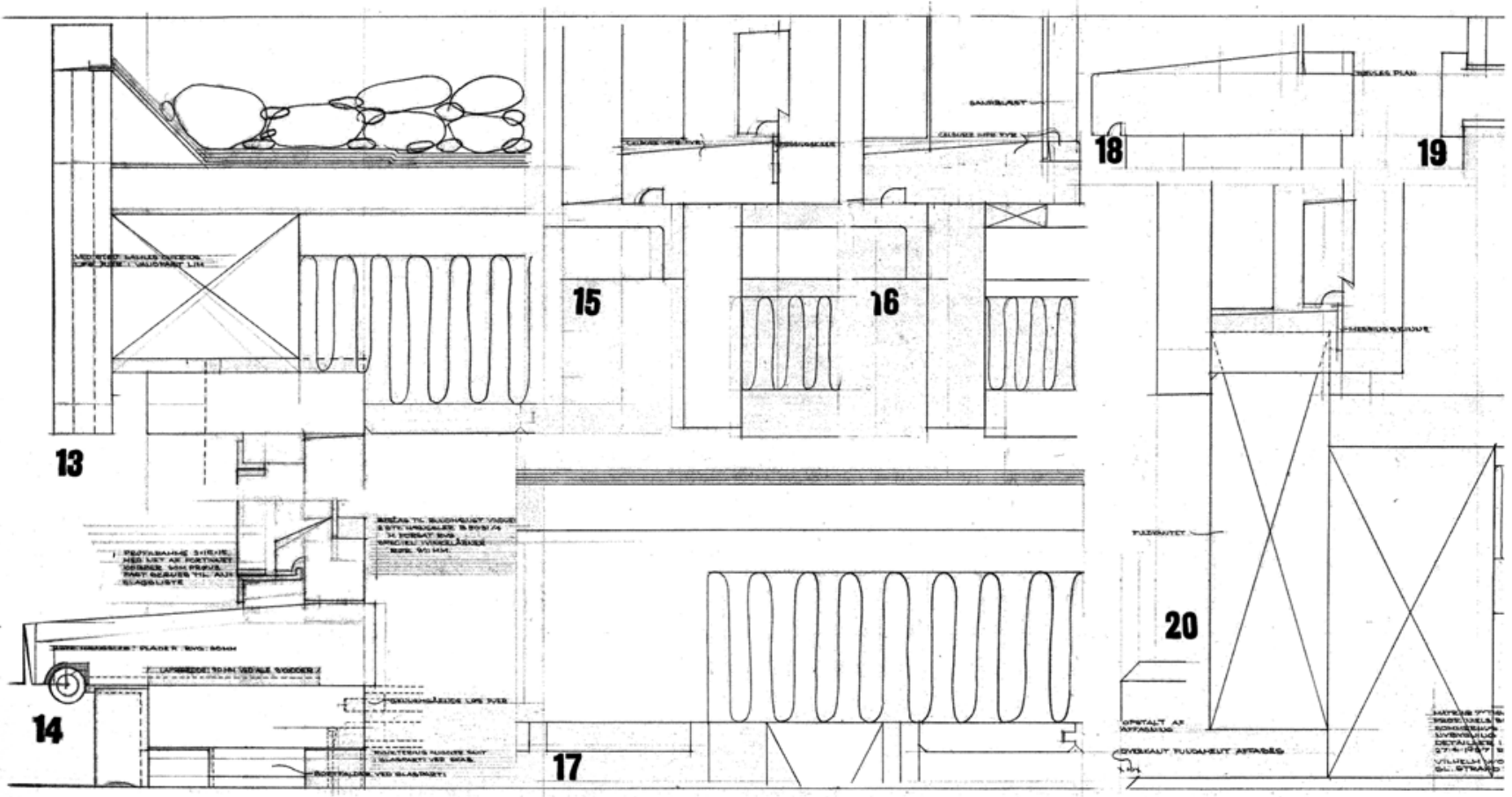


${ }^{55}$ La casa tradicional japonesa se considera algo temporal. Debido a las lluvias torrenciales y la humedad de hasta un $90 \%$ en verano, debe elevarse del suelo y adaptarse a los cambios mediante mecanismos ligeros $y$ fáciles, para ventilarse o cerrarse según convenga. En Japón se construye en madera no por una tradición anquilosada, ni por falta de otros materiales, sino porque es el materia que mejor se adecúa a una construcción no permanente, barata y sencilla.

${ }^{\mathbf{5 6}}$ Fue una figura fundamental para entender la evolución arquitectónica del entorno escandinavo frente al camino seguido por el Movimiento Moderno en el resto de Europa.

57 (ASPLUND, E.G., "Byggmastaren" Estocolmo: 1931 citado en ASPLUND, E.G., et al. Madrid: p. 177

58 (Ibidem p. 183)

$\mathbf{5 9}$ Wright habia tomado la idea del libro The Book of tea de Okakura, que le creó un gran impacto, y fue tan importante para él como sus encuentros con el pabellón japonés de Phoenix y las postales de Hiroshige. En el libro Okakura desvela cómo la esencia de la casa de té no está en el edificio en sí, sino en el vacío generado en él. Este concepto y comprender que los edificios no consisten en cuatro paredes y un tejado, sino en el espacio que habita entre ellos, fue una revelación. Wohlert sigue esta concepción y maneja en e proyecto diferentes límites virtuales, idea que habita en el corazón de la cultura japonesa, donde se da todo un mundo de relaciones.

60 “ (...)The works of man reveals his nature (...) " KAHN, L.I. What will be has always been: The Words of Louis I. Kahn. p. 82, En los L.I.K. Studios University de Pennsylvania 1969

[27] Croquis de los inicios del proyecto del pabellón Nits Bohr. Autor Vilhelm Wohlert. PARDEY, J., BO, J., JENSEN, K. and WOHLERT, V., Louisiana and Beyond: The Work of Vilhelm Wohlert. Hellerup (Dinamarca): Blondal, 2007, p. 16.

[28] Fotografía Casa Breuer II, New Canaan. Fotografia de Pedro E. Guerrero. Marcel Breuer papers, 1920-1986. Archives of American Art, Smithsonian Institution. Digital ID: 8215 http://www.aaa.si.edu/collections/items/deta// breuer-house-new-canaan-conn-8215

[29] Estación en Bornholm por Kay Fisker y Aage Rafn. SHERIDAN, M., Mesterværker, Enfamiliehuset i Dansk Arkitekturs Guldalder. Copenhage: Strandberg Publishing, 2011, p. 20. Fotografia original propiedad de la Biblioteca de Arte Nacional Danesa, Archivo de fotografias histórico artísticas.

[30] Detalles constructivos sección horizonta pabellón Niels Bohr. Autor Vilhelm Wohlert. PARDEY, J., et al., Louisiana and Beyond: The Work of Vilhelm Wohlert. Hellerup (Dinamarca): Blondal, 2007, p. 27

[31] Detalles constructivos sección vertical pabellón Niels Bohr. Autor Vilhelm Wohlert. PARDEY, J., et al., Louisiana and Beyond: The Work of Vilhelm Wohlert. Hellerup (Dinamarca): Blondal, 2007, p. 27

[32] Casa propia del arquitecto Jørgen Bo, 1954, Hjortekaer (Dinamarca). Fotografia de Else Tholstrup. MONIES, F., Træ Og Arkitektur. Copenhage: Træbranchernes oplysningsråd og Arkitektens Forlag, 1958, p. 30.
1955 en Gentofte del arquitecto Erik Christian Sørensen, la casa propia de verano 1960 de Erik Korshagen en Korshage... Se pudo repetir numerosas veces y desarrollar acomodándose a variaciones de programa o diferentes situaciones, pero es único. Fue el primer proyecto edificado de Wohlert y el único construido exclusivamente en madera, pero será el preludio del Museo Louisiana y resto de proyectos que desarrollará en su mayor parte junto con su amigo el arquitecto danés Bo, donde será una constante el uso de formas abstractas de contrastado color que aumentaran la experiencia de la naturaleza. [33]

La casa de invitados alojó a amigos, científicos y familiares del profesor Bohr hasta su muerte en 1962. En la actualidad continúa teniendo su función original y pertenece a sus descendientes, que la mantienen con devoción. Forma parte de la lista de edificios protegidos en 2004 por la Agencia Danesa por la Cultura para ser preservada en el futuro.

Tal y como Louis Kahn (1901-1974) decía "(...)Los trabajos del hombre revelan su naturaleza (...)"60. Del trabajo de Vilhelm Wohlert se desprende su talento individual, formación como diseñador de muebles, sentido de la moderación y preferencia por lo sencillo. Su arquitectura, definida por él mismo como ascética, carece de afectación, de arrogancia, de fingimiento, pero a la vez está llena de sensibilidades y sutilezas. Las formas modulares unidas a todas estas variadas y diferentes influencias en su trabajo tienen un carácter universal. Si bien el cuidado y el interés por el confort humano es una preocupación eterna, la habilidad de este proyecto por adaptarse a los cambios lo convierte en un modelo para el futuro. El contacto y encuentro con la naturaleza para el visitante de sus obras, que ha aprendido a percibir el espíritu del lugar, puede inducir al entendimiento de que naturaleza, vida y arquitectura están unidas indisolublemente.

[32]

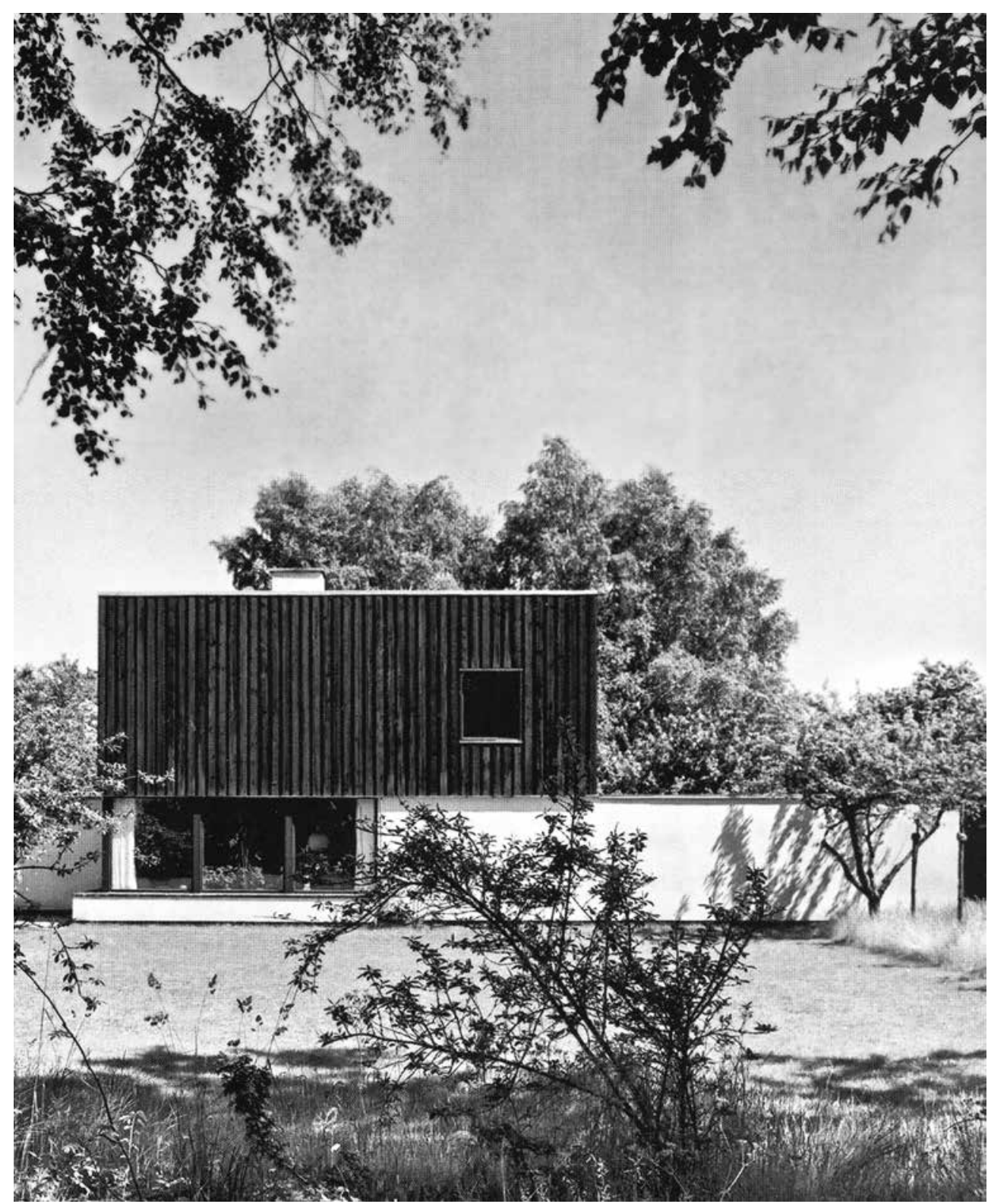

